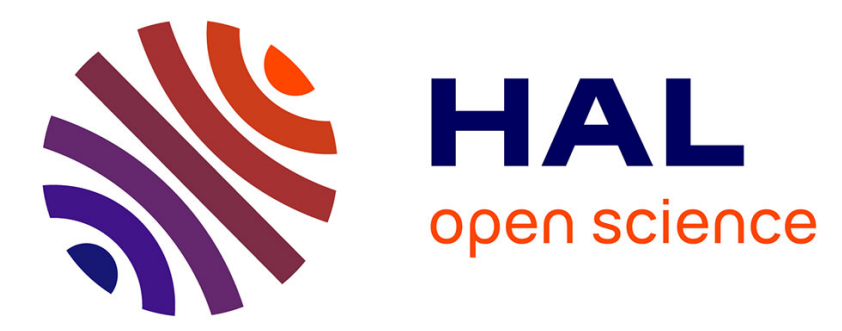

\title{
Structure-based nomenclature for irregular linear, star, comb, and brush polymers (IUPAC Recommendations 2020)
}

Jiazhong Chen, Edward S Wilks, Alain Fradet, Karl-Heinz Hellwich, Roger C. Hiorns, Tamaki Nakano, Claudio G dos Santos, Patrick Theato

\section{To cite this version:}

Jiazhong Chen, Edward S Wilks, Alain Fradet, Karl-Heinz Hellwich, Roger C. Hiorns, et al.. Structurebased nomenclature for irregular linear, star, comb, and brush polymers (IUPAC Recommendations 2020). Pure and Applied Chemistry, 2021, 93 (9), pp.963 - 995. 10.1515/pac-2020-0103 . hal03432745

\section{HAL Id: hal-03432745 \\ https://hal.science/hal-03432745}

Submitted on 17 Nov 2021

HAL is a multi-disciplinary open access archive for the deposit and dissemination of scientific research documents, whether they are published or not. The documents may come from teaching and research institutions in France or abroad, or from public or private research centers.
L'archive ouverte pluridisciplinaire $\mathbf{H A L}$, est destinée au dépôt et à la diffusion de documents scientifiques de niveau recherche, publiés ou non, émanant des établissements d'enseignement et de recherche français ou étrangers, des laboratoires publics ou privés. 


\title{
IUPAC Recommendations
}

Jiazhong Chen*, Edward S. Wilks*, Alain Fradet, Karl-Heinz Hellwich, Roger C. Hiorns, Tamaki Nakano, Claudio G. dos Santos and Patrick Theato

\section{Structure-based nomenclature for irregular linear, star, comb, and brush polymers (IUPAC Recommendations 2020)}

https://doi.org/10.1515/pac-2020-0103

Received January 10, 2020; accepted January 25, 2021

\begin{abstract}
The existing recommendations for the structure-based nomenclature of regular single-strand organic polymers are extrapolated to complex polymers. The key proposal is that polymeric moieties may be named substituents. The types of polymers covered include linear and branched polymers containing more than one block of a single type of constitutional repeating unit (CRU) and branched polymers containing a main chain from which one or more polymeric side chains emanate.
\end{abstract}

Keywords: Brush-shaped polymers; comb-shaped polymers; IUPAC Division of Chemical Nomenclature and Structure Representation; IUPAC Polymer Division; linear polymers; Nomenclature Recommendations; starshaped polymers; structure-based polymer names.

\section{SCB-1 Introduction}

Between 1984 and 2012, the IUPAC published several documents containing recommendations for the nomenclature of a wide variety of polymer types such as regular linear single-strand [1, 2], irregular singlestrand [2,3], organic regular double-strand [2, 4], and cyclic organic macromolecules [5], non-linear macromolecules and macromolecular assemblies $[2,6]$, and quasi-single-strand inorganic and coordination polymers [7]. More recently a document on source-based nomenclature for single-strand homopolymers and copolymers was published in 2016 [8], and a document on nomenclature for dendrimers and hyperbranched polymers was published in early 2019 [9]. However, structure-based nomenclature for certain types of

Article note: This manuscript was prepared in the framework of IUPAC projects 2013-031-3-800 and 2019-036-1-800. Sponsoring bodies: IUPAC Chemical Nomenclature and Structure Representation Division and IUPAC Polymer Division: see more details on page 994.

*Corresponding authors: Jiazhong Chen, DuPont Science \& Innovation, Information \& Data Sciences, Experimental Station, Rte. 141 \& Henry Clay Road, Wilmington, DE 19880, USA, e-mail: Jiazhong.Chen@dupont.com; and Edward S. Wilks, 4113 Meriden Drive, Canterbury Hills, Hockessin, DE 19707, USA, e-mail: tedwilks@comcast.net

Alain Fradet, Institut Parisien de Chimie Moléculaire, Sorbonne Université, Chimie des Polymères-Courrier 185, 4 Place Jussieu, F-75252 Paris Cedex 05, France

Karl-Heinz Hellwich, Beilstein-Institut zur Förderung der Chemischen Wissenschaften, Trakehner Staße 7-9, 60487 Frankfurt, Germany

Roger C. Hiorns, CNRS/Univ Pau \& Pays Adour, Institut des Science Analytiques et Physico-Chimie pour l'Environnement et les Materiaux, Pau, France

Tamaki Nakano, Institute for Catalysis, Hokkaido University, N21W10, Kita-ku, Sapporo 001-0021, Japan

Claudio G. dos Santos, Departamento de Quimica - ICEB, Campus Morro do Cruzeiro, Federal University of Ouro Preto, 35400-000 Ouro Preto Brazil

Patrick Theato, Institute for Chemical Technology and Polymer Chemistry, Karlsruhe Institute of Technology (KIT), Engesser Str. 18, D-76131 Karlsruhe, Germany 
branched polymers with three or more blocks of identical constitutional repeating units (CRUs) (three-arm star, four-arm star or brush, etc.) has not yet been fully addressed by the IUPAC. This document provides recommendations for structure-based nomenclature of polymers comprising a linear single strand with two or more blocks of identical CRUs and branched strands (star, comb, and brush-like) containing three or more blocks of identical CRUs connected by a central non-repeating junction unit. This document also revises some of the rules given in the document for regular linear single-strand molecules [1], in particular, rule 22 on polymer chains as substituents.

\section{SCB-2 Definitions}

Some of the terms defined in this section are extractions of the essence of primary definitions in references [2, 10]. This is done to avoid tedious cross-referencing, which should help the reader more easily understand the information relevant in the context of this document. All such instances are indicated. These definitions are not new primary definitions.

Cross-references to terms defined elsewhere in this section are denoted in italic typeface.

\section{SCB-2.1 block}

Portion of a macromolecule, comprising many constitutional units, which has at least one constitutional or configurational feature which is not present in the adjacent portions $[2,10]$.

\section{SCB-2.2 block macromolecule}

Macromolecule which is composed of blocks in linear sequence $[2,10]$.

\section{SCB-2.3 block polymer}

Polymer composed of block macromolecules $[2,10]$.

\section{SCB-2.4 brush macromolecule}

Macromolecule comprising a main chain with tetrafunctional or higher functional branch points from each of which linear side chains emanate.

Note 1: If the subchains between the branch points of the main chain and the terminal subchains of the main chain are identical with respect to constitution and the degree of polymerization and the side chains are identical with respect to constitution and the degree of polymerization, the macromolecule is termed a regular brush macromolecule.

Note 2: If all of the branch points are of functionality equal to three, the macromolecule is termed a comb macromolecule.

\section{SCB-2.5 brush polymer}

Polymer composed of brush macromolecules.

Note: The term should not be confused with polymer brush, which is commonly used to describe polymers attached to a substrate. 


\section{SCB-2.6 comb macromolecule}

Macromolecule comprising a main chain with multiple trifunctional branch points from each of which a linear side chain emanates $[2,8,10]$.

Note 1: If the subchains between the branch points of the main chain and the terminal subchains of the main chain are identical with respect to constitution and the degree of polymerization and the side-chains are identical with respect to constitution and the degree of polymerization, the macromolecule is termed a regular comb macromolecule.

Note 2: If at least some of the branch points are of functionality greater than three, the macromolecule is termed a brush macromolecule; modified from [2, 10] and Gold Book online, 2014 entry [11].

\section{SCB-2.7 comb polymer}

Polymer composed of comb macromolecules [2, 10].

\section{SCB-2.8 constitutional unit (CU)}

An atom or a group of atoms (with pendant atoms or groups, if any) comprising a part of the essential structure of a macromolecule, an oligomer molecule, a block, or a chain $[1,2,4,10]$.

\section{SCB-2.9 constitutional repeating unit (CRU)}

The smallest constitutional unit, the repetition of which constitutes a regular macromolecule, a regular oligomer molecule, a regular block, or a regular chain $[1,2,4,10]$.

\section{SCB-2.10 copolymer}

Polymer derived from more than one species of monomer or apparent monomer [8].

Note: Adapted from $[2,10]$ (see SB-1.8 [8])

\section{SCB-2.11 end-group}

A constitutional unit that is an extremity of a macromolecule or oligomer molecule $[1,2,10]$.

\section{SCB-2.12 irregular polymer}

Polymer composed of irregular macromolecules, i.e., macromolecules, the structures of which essentially comprise the repetition of more than one type of constitutional unit, or macromolecules, the structures of which comprise constitutional units not all connected identically with respect to directional sense.

Note: Combination of definitions 1.5 (irregular macromolecule) and 2.16 (irregular polymer) in [2, 10].

\section{SCB-2.13 junction unit}

Non-repeating atoms or non-repeating groups of atoms between blocks in a block macromolecule $[2,10]$. 


\section{SCB-2.14 locant}

Numeral or letter or a combination of both that identifies position(s) in a structure.

Note 1: A locant appears in a name or general expression such as '2-substituted'.

Note 2: Modified from $[1,2,8]$.

\section{SCB-2.15 senior constitutional repeating unit (S-CRU)}

More (most) senior CRU of a structure of a macromolecule or oligomer molecule containing two or more different types of CRUs.

Note 1: The $C R U$ beginning with the subunit of highest (higher) seniority is chosen as the $S$-CRU.

Note 2: If $C R U$ s begin with an identical subunit, the choice depends on the seniority of the remaining subunits and the number and position of substituents [1, 2].

Note 3: Two examples of the chosen S-CRUs are

$$
\begin{aligned}
& \text { 1) }-\left[\mathrm{O}-\mathrm{CH}_{2} \mathrm{CH}_{2}\right]_{n}-\text { not }-\left[\mathrm{N}-\mathrm{CH}_{2} \mathrm{CH}_{2}\right]_{n}- \\
& \text { 2) }-\left[\mathrm{O}-\mathrm{COCH}_{2}\right]_{n}-\text { not }-\left[\mathrm{O}-\mathrm{CH}_{2} \mathrm{CH}_{2}\right]_{n}^{-}
\end{aligned}
$$

\section{SCB-2.16 preferred constitutional repeating unit (P-CRU)}

Constitutional repeating unit (CRU) written with the subunits in a linear series from the highest (higher) seniority to the lowest (lower) or as close as possible by the shortest path.

Note 1: This definition is based on descriptions of methods to reach the $P$-CRU $[1,2]$.

Note 2: The P-CRU is chosen with the lowest possible locant(s) for the substituents.

Note 3: Two examples of the chosen P-CRUs are

$$
\begin{aligned}
& \text { 1) }-\left[\mathrm{O}-\mathrm{CH}_{2} \mathrm{CH}_{2}-\mathrm{S}-\mathrm{CH}_{2} \mathrm{CH}_{2}\right]_{n}-\text { not }-\left[\mathrm{S}-\mathrm{CH}_{2} \mathrm{CH}_{2}-\mathrm{O}-\mathrm{CH}_{2} \mathrm{CH}_{2}\right]_{n}- \\
& \text { 2) }-\left[\mathrm{O}-\mathrm{CH}_{2} \mathrm{CH}_{2}-\mathrm{O}-\mathrm{CH}_{2} \mathrm{CH}_{2} \mathrm{CH}_{2}\right]_{n}-\text { not }-\left[\mathrm{O}-\mathrm{CH}_{2} \mathrm{CH}_{2} \mathrm{CH}_{2}-\mathrm{O}-\mathrm{CH}_{2} \mathrm{CH}_{2}\right]_{n}-
\end{aligned}
$$

\section{SCB-2.17 regular polymer}

Polymer composed of regular macromolecules, regular star macromolecules, or regular comb macromolecules. Note: A polymer consisting of star macromolecules with arms identical with respect to constitution and the degree of polymerization is considered to be regular; see Note 2 to the definition of a star macromolecule [10]. Analogously, a polymer consisting of comb macromolecules with the sub-chains between the branch points of the main chain and the terminal sub-chains of the main chain identical with respect to constitution and the degree of polymerization and the side chains identical with respect to constitution and the degree of polymerization is considered to be regular; see Note 1 to the definition of a comb macromolecule [10].

\section{SCB-2.18 seniority}

Priority in a set of atoms or groups of atoms according to a prescribed order [1, 2]. 


\section{SCB-2.19 single-strand polymer}

Polymer, the macromolecules of which are single-strand macromolecules $[2,10]$.

\section{SCB-2.20 star macromolecule}

Macromolecule containing a single branch point from which linear chains (arms) emanate [2, 10].

Note 1: A star macromolecule with $\mathrm{n}$ linear chains (arms) attached to the branch point is termed an $\mathrm{n}$-star macromolecule, e.g., five-star macromolecule.

Note 2: If the arms of a star macromolecule are identical with respect to constitution and the degree of polymerization, the macromolecule is termed a regular star macromolecule.

Note 3: If different arms of a star macromolecule are composed of different monomeric units, the macromolecule is termed a variegated star macromolecule.

\section{SCB-2.21 star polymer}

Polymer composed of star macromolecules $[2,10]$.

\section{SCB-2.22 subunit}

Largest main-chain (backbone) segment of the constitutional repeating unit (CRU) that can be named a single unit under organic nomenclature rules. This may be a ring or a ring system, a heteroatom or a heteroatom chain, or an acyclic carbon chain $[1,2]$.

\section{SCB-3 CRU bracket shift and existing IUPAC nomenclature recommendations}

The IUPAC document of recommendations for the nomenclature of regular linear single-strand organic polymers [1] provides detailed rules to name polymers. Since these nomenclature rules are important for this document, the fundamental principles are recalled here.

There are many ways to graphically represent the CRU for most polymer chain structures. To provide a unique and unambiguous polymer name, the most crucial step is to identify the preferred CRU. The preferred CRU is selected by applying the rules to the structure of a polymer chain. The preferred CRU will be the one that starts with the most senior subunit, and from this subunit, proceeds toward the subunit next in seniority or by the shortest possible path to another occurrence of the most senior subunit. Recommendations for the selection of the preferred CRU can be found in rules 13-16 in [1].

The preferred CRU of a polymer must be named before the complete polymer can be named. A preferred CRU is named by using the name of each subunit that comprises the CRU based on the IUPAC rules of organic nomenclature [12]. A new IUPAC document of preferred names of constitutional units for use in structure-based names of polymer [13] can be consulted while naming a CRU. The document provides the preferred name for each CRU used for naming polymers according to IUPAC nomenclature rules.

The name of a polymer is made by prefixing the name of the preferred CRU with 'poly' and the preferred CRU name enclosed in parentheses or brackets. For polymer $[A B C]_{n}$, in which $A, B$, and $C$ are the subunits that comprise the preferred CRU (ABC), in order from the highest to lowest seniority, from left to right, is named poly(ABC). If end groups are present in the polymer, rule 21 in [1] is adopted to name the polymer. End-groups 
are specified by prefixes placed ahead of the name of the polymer. The end-group connected to the subunit of the highest seniority in the CRU is designated as $\alpha$ and the other end-group is designated as $\omega$. If there is a choice, the end-group with the name starting earlier in the alphabet should be cited first.

For example, for a polymer with the structure

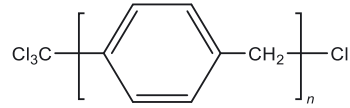

the preferred $\mathrm{CRU}$ is $-\mathrm{C}_{6} \mathrm{H}_{4}-\mathrm{CH}_{2}-$, not $-\mathrm{CH}_{2}-\mathrm{C}_{6} \mathrm{H}_{4}$-, because the carbocyclic-ring diradical $-\mathrm{C}_{6} \mathrm{H}_{4}$ - is senior to the acyclic diradical - $\mathrm{CH}_{2}$. The name of the preferred CRU is 1,4-phenylenemethylene. The polymer is named $\alpha$ (trichloromethyl)- $\omega$-chloropoly(1,4-phenylenemethylene).

However, at the current time, the nomenclature of complex polymer structures is not easy because of the sometimes conflicting constraints imposed on the seniorities of subunits in the backbone, junction units, and endgroups.

For example,<smiles>COCCOCCOC</smiles>

There are two possible names available for this polymer depending on the structural representations: $\alpha$-(chloromethyl)- $\omega$-methoxypoly(oxyethylene) or $\alpha$-methyl- $\omega$-(chloromethoxy)poly(oxyethylene)

In order to resolve this problem, it is recommended that the parentheses or brackets be shifted to facilitate naming. This process is called 'bracket shift'. The term 'bracket shift' and the corresponding adjectival forms such as 'bracket shifted', 'bracket shiftable', etc. are proposed to convey the concept that for some end-capped CRUs, the enclosing parentheses or brackets may be moved in such a manner that the resulting CRU is still drawn according to the existing recommendations [1], but movement of the enclosing parentheses or brackets results in different end-groups, e.g., methoxy versus methyl. The simple examples below (Table 1) demonstrate this process of parenthesis or bracket shifting and the impact it can have on the approach used to name the polymer.

Table 1: Examples of bracket-shiftable poly(alkanediyl oxide)s.

CRU<smiles>CC(C)(C)OCCCO</smiles><smiles>CCCC(=O)C(C)OCCC(C)(C)O</smiles><smiles>COCCOC(C)=O</smiles><smiles>C=C(C)C(=O)OCCOC(C)=O</smiles><smiles>CCOCCCC(C)OC</smiles>

Bracket-shifted CRU<smiles>COCCC(C)(C)OC</smiles><smiles>CCCCCOC(=O)CCO</smiles><smiles>CC(=O)OCCOC(C)(C)C</smiles><smiles>C=C(C)C(=O)OCCOC(C)=O</smiles><smiles>CCOCCCCOC</smiles>

Bracket-shifted CRU with the senior subunit placed leftmost<smiles>COC(C)(C)CCOC(C)C</smiles><smiles>CCC(=O)OCCOC(C)C</smiles><smiles>CC(=O)OCCOC(C)(C)C</smiles><smiles>C=C(C)C(=O)OCCOC(C)=O</smiles><smiles>CCOC(C)(C)CCCOC(C)(C)C</smiles> 
Note: Chemical Abstracts Service (CAS) considers the preservation of bracket shiftability in representations of poly(alkanediyl oxide)s to be a guiding principle of high priority, whereas the IUPAC recommendation is that the CRU must contain the maximum number of repeating units, which means that additional repeating units may not be used outside the CRU parentheses or brackets in order to achieve bracket shiftability (see Nomenclature Recommendation 1 below). For instance, in the IUPAC, the structure representation of ${ }_{\mathrm{H}_{3} \mathrm{C}}{ }^{\circ} \mathrm{N}_{\mathrm{NH}_{2}}$ is not bracket-shiftable. The polymer nomenclature system of the CAS, however, considers that it is bracket-shiftable after adding a repeating unit outside the CRU bracket.<smiles>C=CC(C)(C)OCCOCCOCCOCCN</smiles>

The right-hand side structural representation is considered as the preferred structural representation for the polymer by the CAS.

When the sequence of subunits comprising the CRU of a polymer and the oxygen atom immediately to the right of the closing parenthesis or bracket of the CRU has no lateral symmetry, the CRU is not bracket-shiftable.

Examples of non-bracket-shiftable polymers:<smiles>CCOC(=O)CCCC(C)C(=O)OC</smiles><smiles>C=C(C)C(=O)OCCOC(=O)ONC(=O)OCC(=O)O</smiles>

The examples given under rule 21 in [1] set forth two key points that address the issue of bracket shift in CRUs in which bracket shift is possible. Since these are both fundamentally important in this document, they are repeated here as formal IUPAC Recommendations.

\section{Nomenclature Recommendation 1}

When defining a preferred CRU for a polymer, a principle of maximization should be followed. The preferred CRU should represent the maximum number of repeating units in the polymer chain.

Note: This recommendation is an extension of the rules in reference [1], in which the principle of maximizing the number of repeating units in the preferred CRU is not explicit in this respect, but only implied.

\section{Nomenclature Recommendation 2}

In a bracket-shiftable polymer comprising a single type of CRU and two different end-groups, the endgroup designated as $\alpha$ is that attached to the left-hand side of the CRU, written as described in the preceding rules, and the other end-group is designated as $\omega$, and the end-groups are cited in order. If there is a choice, the end-group with the name starting earlier in the alphabet should be cited first (from rule 21 in [1]).

\section{Example:}

$\alpha$-hydro- $\omega$-methoxypoly(oxyethylene)<smiles>COCCOC</smiles>

For the bracket-shifted structural representation, the name is $\alpha$-methyl- $\omega$-hydroxypoly(oxyethylene).<smiles>COCCCCCCO</smiles>

Therefore, the correct name for this polymer is $\alpha$-hydro- $\omega$-methoxypoly(oxyethylene) because the name is earlier in the alphabet. 
Four more examples are shown in Table 2.

Table 2: Examples illustrating Nomenclature Recommendation 2.

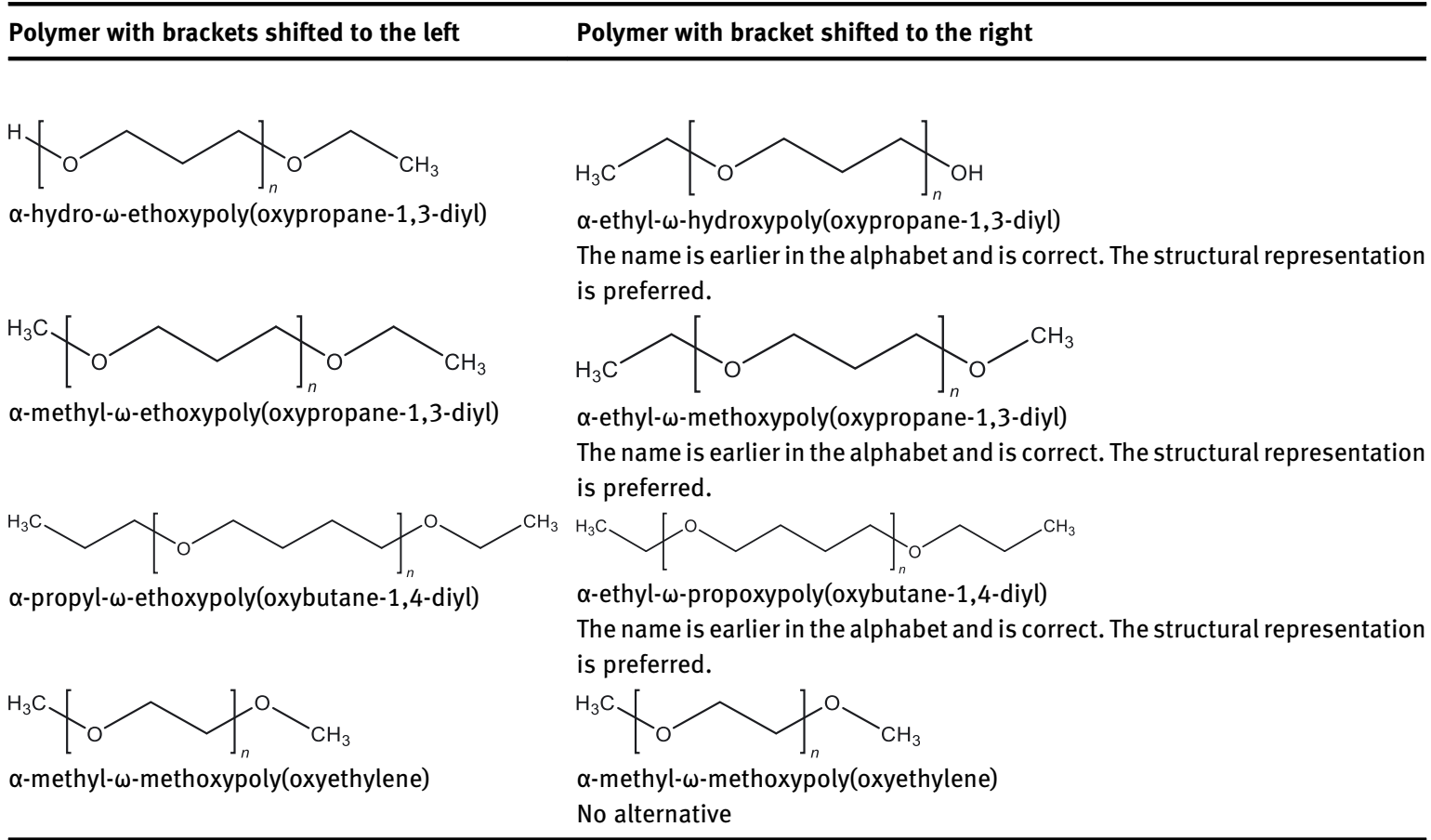

\section{Nomenclature Recommendation 3}

In an irregular polymer containing two or more identical bracket-shiftable CRUs and a central nonrepeating junction unit, the enclosing parentheses or brackets for all occurrences of the CRU should be bracketshifted inward toward the central non-repeating junction unit, which means that they would also be bracketshifted towards each other. End-groups may or may not be present.

Such polymers can be represented generically using expressions such as:

$\mathrm{EG}-[\mathrm{CRU}]_{n}-\mathrm{J}-[\mathrm{CRU}]_{m}-\mathrm{EG}$

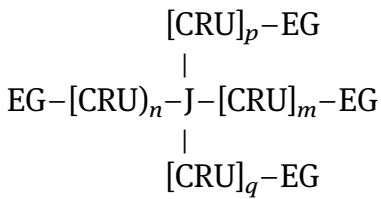

in which EG is an end-group, $\mathrm{J}$ is a non-repeating junction unit, and CRU is a constitutional repeating unit. If all CRUs can be bracket-shifted with no change in the structure within the CRU itself, they should all be bracket-shifted toward the central non-repeating junction unit. Thus, they are also all bracket-shifted toward each other. Polyethers usually fall into this category.

\section{Example:}

$\alpha, \alpha^{\prime}$-hexanedioylbis[ $\omega$-methoxypoly(oxyethylene)]

$$
\left.\mathrm{CH}_{3} \mathrm{O}-\left[\mathrm{CH}_{2} \mathrm{CH}_{2} \mathrm{O}\right]_{n}-\mathrm{CO}\left[\mathrm{CH}_{2}\right]_{4} \mathrm{CO}-\left[\mathrm{OCH}_{2} \mathrm{CH}_{2}\right)\right]_{m}-\mathrm{OCH}_{3}
$$

Note: Not $\omega, \omega^{\prime}$-bis(hexanedioyldioxy)bis[ $\alpha$-methylpoly(oxyethylene)], which would be the name for the representation $\mathrm{CH}_{3}-\left[\mathrm{OCH}_{2} \mathrm{CH}_{2}\right]_{n}-\mathrm{OCO}\left[\mathrm{CH}_{2}\right]_{4} \mathrm{COO}-\left[\mathrm{CH}_{2} \mathrm{CH}_{2} \mathrm{O}\right]_{m}-\mathrm{CH}_{3}$ (incorrect bracket shift). 
When the end-groups are identical, the name for the central non-repeating junction unit, expressed as a multiplying group, should be inserted before the names of the end-groups. Examples of this nomenclature style were published previously [1], although the "rule" thereby implied was never introduced as a formal IUPAC Recommendation. Polymers for which the end-groups are different are named by a modified method, which is covered later in this document.

This document extends these two fundamental recommendations and applies them to the types of irregular single-strand, star, comb, and brush polymers discussed below.

\section{Example:}

$\alpha, \alpha^{\prime}-1,4$-phenylenebis[ $\omega$-(prop-2-enoyloxy)poly(oxyethylene)]<smiles>C=CC(=O)OCCOc1ccc(OCCOC(=O)C=C)cc1</smiles>

Alternative representations, such as the ones shown below, in which at least one of the CRUs is bracketshifted away from the central non-repeating junction unit, are discouraged:<smiles>C=CC(=O)OCCOc1ccc(OCCOC(=O)C=C)cc1</smiles>

\section{SCB-4 Polymeric moiety within a substituent or an end-group}

In substitutive nomenclature, complex substituents (i.e., those containing two or more subunits) are named in such a way that components are cited in order from the periphery toward the point of attachment [12].

\section{Example:}

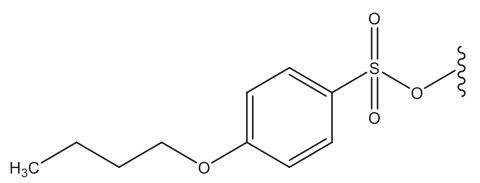

Name: $\{[(4-$ butoxyphenyl)sulfonyl]oxy $\}$

This document logically extends this nomenclature principle to complex substituents containing a polymeric moiety.

\section{Nomenclature Recommendation 4}

(1) Substituents containing oligomeric or polymeric moieties are named according to the principles of substitutive nomenclature in such a way that their components are cited in order from the periphery toward the point of attachment.

(2) Names of CRUs within substituents are never "reversed," i.e., the subunits that comprise a CRU are never cited in inverse order. For clarity, the connective "- $\alpha$-yl-" or "- $\omega$-yl”, as appropriate, should be inserted in the name between the CRU and the next subunit or between the CRU and the point of attachment.

Note: This is a change to Rule 22 in [1] in which reversal was obligatory because the "- $\alpha$-yl-" and "- $\omega$-yl" differentiation had not been proposed and did not exist at the time of publication of [1]. 
The order of seniority of subunits is of primary importance in the generation of a polymer name. The basic order of seniority of subunits is heterocyclic rings and ring systems $>$ heteroatom chains $>$ carbocyclic rings and ring systems $>$ acyclic carbon chain [1].

Detailed rules of seniority of subunits were published previously [1]

\section{Example:}

(unidentified group)-[ $\left[\mathrm{CH}_{2} \mathrm{CH}_{2} \mathrm{O}\right]_{n}-\mathrm{SO}_{2}$-(attachment point)<smiles>CC(C)(C)CCOS(C)(=O)=O</smiles>

Name: [poly(oxyethylene)- $\alpha$-yl]sulfonyl

not [poly(ethyleneoxy)- $\alpha$-yl] sulfonyl, in which the subunit seniority rule for the CRU is not followed.

\section{Example:}<smiles>CCC(=O)Oc1ccc(S(=O)(=O)OC)cc1</smiles>

Name: $\{[(4-\{$ poly[oxy(1-oxoethylene) $]-\alpha-y l\}$ phenyl)sulfonyl]oxy $\}$

Note: Use of the connective "- $\alpha$-yl-" removes any ambiguity with regard to which end of the CRU is closer to the point of attachment. Compare the example above with the one below:

\section{Example:}<smiles>COC(=O)Cc1ccc(S(=O)(=O)OC)cc1</smiles>

Name: $\{[(4-\{$ poly[oxy(1-oxoethylene)]- $\omega$-yl $\}$ phenyl)sulfonyl]oxy\}

Note: Use of the connective "- $\omega$-yl-" in this example reinforces the point that the CRU, as a whole, has its senior subunit remote from the point of attachment of the substituent.

The value of the connectives "- $\alpha$-yl-" and "- $\omega$-yl-" will become even clearer in names for substituents containing CRUs that also have other subunits more remote from the point of attachment.

\section{Nomenclature Recommendation 5}

Substituents should be named according to organic nomenclature principles in such a way that components are cited in order from the periphery toward the point of attachment. Polymeric moieties within substituents should be named as recommended in Recommendation 3. All subunits more remote from the point of attachment than CRUs should be named by citation in order, starting from the most remote subunit. These are then parenthesized, bracketed, or braced (according to the existing IUPAC recommendations [1]) and attached to the CRU at the end remote from the point of attachment of the substituent.

\section{Example:}

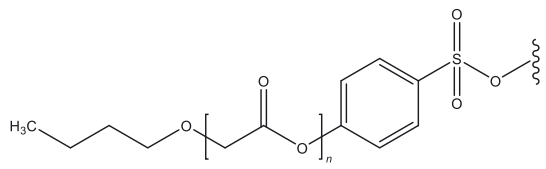

Name: $\{[(4-\{\omega$-butoxypoly[oxy(1-oxoethylene)]- $\alpha$-yl\}phenyl)sulfonyl] $]$ oxy $\}$ 


\section{Example:}<smiles>CCCCOC(=O)Cc1ccc(S(=O)(=O)OC)cc1</smiles>

Name: $\{[(4-\{\alpha$-butylpoly[oxy(1-oxoethylene)]- $\omega$-yl\}phenyl)sulfonyl]oxy\}

Note: Use of the connective "- $\omega$-yl-" between the CRU and the phenylene moiety in this example reinforces the point that the CRU, as a whole, has its senior subunit remote from the point of attachment of the substituent.

\section{Nomenclature Recommendation 6}

Substituents should be named according to organic nomenclature principles in such a way that components are cited in order from the periphery toward the point of attachment. Bracket-shiftable polymeric moieties within substituents should be named as recommended in Recommendation 3. All subunits more remote from the point of attachment than CRUs should be named by citation in order, starting from the most remote subunit. These are then parenthesized, bracketed, or braced (according to the existing IUPAC recommendations [1]) and attached to the CRU at the end remote from the point of attachment of the substituent. For consistency in the depiction of representations, parentheses, brackets, or braces enclosing bracketshiftable CRUs should be bracket-shifted toward the point of attachment of the substituent.

\section{Example:}

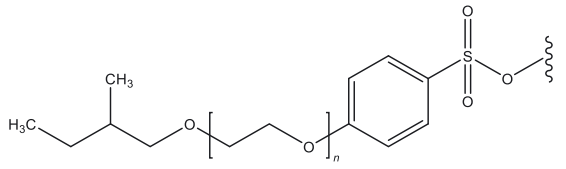

Name: [(\{4-[ $\omega$-(2-methyl)butoxypoly(oxyethylene)- $\alpha$-yl]phenyl\}sulfonyl)oxy]

Note: The structural representation and the corresponding name for the bracket-shifted alternative, $\{[(4-\{[\alpha-(2-m e t h y l) b u t y l p o l y(o x y e t h y l e n e)-\omega$-yl] oxy $\}$ phenyl)sulfonyl $]$ oxy $\}$ are discouraged.<smiles>CCC(C)COCCOc1ccc(S(=O)(=O)OC)cc1</smiles>

Note: Examples of polymer chains as substituents have been previously published [1], but the issue of bracket shift was not addressed.

Nomenclature Recommendations 3, 4, and 5 can be also applied to end-groups containing polymeric moieties. Examples are given later in this document.

\section{SCB-5 Simple versus complex non-repeating junction units}

A non-repeating junction unit in a polymer is a multivalent group inserted between polymeric moieties in structure-based representation of polymers. Generically, it is represented by the letter J in polymers such as EG-CRU-J-CRU-EG. In this document, a simple non-repeating junction unit is defined as one of the following: - A simple subunit with a unitary (i.e., not complex) name.

The subunit may be substituted, either symmetrically or asymmetrically, provided that the skeleton of the subunit retains a "mirror-like" configuration, that is, its lateral reversal within the complete polymer results in name changes only with regard to locant(s) when different end-groups are attached. Examples are oxy, sulfanediyl, methylene, dichloromethylene, ethylene, 1-chloroethylene, propane-1,3-diyl, 1-methylpropane1,3-diyl, propane-1,2,3-triyl, 1-chloropropane-1,2,3-triyl, 2-carboxypropane-1,2,3-triyl, 1,4-phenylene, 2,5-dichloro-1,4-phenylene, 2-chloro-6-methyl-1,4-phenylene, and benzene-1,3,5-triyl. 
Examples of polymer representations containing simple non-repeating junction units:

$$
\begin{aligned}
& \left.\left.\mathrm{HO}-\mathrm{CH}_{2}-\mathrm{CO}-\mathrm{O}-\right]_{n} \mathrm{CH}_{2}-\mathrm{CH}_{2}-\mathrm{CH}_{2}-\mathrm{O}-\mathrm{CO}-\mathrm{CH}_{2}\right]_{m} \mathrm{OH} \\
& \left.\mathrm{HO}-\mathrm{CH}_{2}-\mathrm{CO}-\mathrm{O}-\right]_{n} \\
& \begin{array}{c}
\left.\left.\right|_{\mathrm{CH}} ^{\mathrm{CH}}-\mathrm{O}-\mathrm{O}-\mathrm{CO}-\mathrm{CH}_{2}\right]_{m}^{\mathrm{OH}} \\
\mathrm{CH}_{2}\left[\mathrm{O}-\mathrm{CO}-\mathrm{CH}_{2}\right]_{\rho}^{\mathrm{OH}}
\end{array} \\
& \begin{array}{c}
\mathrm{Cl}-\mathrm{CH}+\mathrm{O}-\mathrm{CO}-\mathrm{CH}_{2} \mathrm{f}_{n}^{\mathrm{OH}} \\
\left.\right|_{\mathrm{CH}} ^{\mathrm{CH}} \mathrm{f}-\mathrm{O}-\mathrm{CO}-\mathrm{CH}_{2} \mathrm{f}_{m}^{\mathrm{OH}} \\
\left.\mathrm{CO}-\mathrm{CH}_{2}\right]_{p}^{\mathrm{OH}}
\end{array}
\end{aligned}
$$

- A symmetrical subunit formed from a combination of unitary names.

Example: in the irregular polymer the junction unit [(1,2-dioxoethylene)bis(sulfanediyl)], although technically "complex", (i.e., it contains more than one type of subunit) is regarded in this document as simple because it may be used as a divalent doubling group.

$$
\left.\left.\mathrm{H}-\mathrm{O}-\mathrm{CO}-\mathrm{CH}_{2}\right]_{n} \mathrm{~s}-\mathrm{CO}-\mathrm{CO}-\mathrm{s}-\mathrm{CH}_{2}-\mathrm{CO}-\mathrm{O}-\right]_{m} \mathrm{H}
$$

A complex non-repeating junction unit is defined in this document as any junction unit other than a simple junction unit as described above. Complex junction units are of two basic types:

- The first type comprises asymmetrical divalent units with complex names, i.e., names formed by the combination of more than one unitary name. Examples are oxymethylene, oxyethylene, oxymethyleneazanediyl, 1,4-phenylenemethylene, sulfanediyl-1,3-phenylene, and oxypropane1,3-diylazanediyl.

- The second type is usually branched. As a general indication, it may be anticipated that when the systematic name for a "parent compound" that can give rise to a polymer containing a complex branched junction unit involves fragmentation, such as the breaking of a carbon-carbon bond, then such fragmentation will also be required in the corresponding complex branched junction unit. Two very common examples of branched non-repeating junction units are those derived from 2-ethyl-2-(hydroxymethyl) propane-1,3-diol and 2,2-bis(hydroxymethyl)propane-1,3-diol, which are encountered in triethers and tetraethers of polymers, especially poly(alkanediyl oxide)s:

\begin{tabular}{ll}
\hline Polyhydric alcohol & Name \\
\hline
\end{tabular}

In organic chemistry, a simple polyvalent substituent group may be used as a multiplier in multiplicative nomenclature. For example,

$$
\mathrm{HO}-\mathrm{CH}_{2}-\mathrm{CH}_{2} \mathrm{O}-\mathrm{CH}_{2} \mathrm{CH}_{2}-\mathrm{OH}
$$


is named 2,2'-oxydiethanol. In this example, oxy, a simple divalent substituent group, is used as a multiplier. The organic multiplicative nomenclature principle is extended in this document to linear, single-strand polymers if there are several occurrences of an identical CRU in identical environments and the principle of multiplication can be applied.

\section{SCB-6 Additional new nomenclature guidelines}

\section{SCB-6.1 Linear, single-strand polymers containing two blocks of an identical CRU}

This type of polymer can be depicted generically as $\mathrm{EG}_{1}-[\mathrm{CRU}]_{n}-\mathrm{J}-[\mathrm{CRU}]_{m^{-}}-\mathrm{EG}_{2}$, in which $\mathrm{EG}_{1}$ and $\mathrm{EG}_{2}$ are two different end-groups, the CRU is a constitutional repeating unit, and $\mathrm{J}$ is a simple or complex non-repeating junction unit. Naming of these polymers depends on several factors, such as whether $\mathrm{J}$ is symmetrical or asymmetrical and whether the CRUs are in identical or non-identical environments, i.e., connected head-tohead, head-to-tail, or tail-to-tail.

\section{SCB-6.1.1 Polymers with two blocks of CRU connected by simple junction unit}

\section{Nomenclature Recommendation 7}

When irregular single-strand polymers of the type represented generically by $\mathrm{EG}_{1}-[\mathrm{CRU}]_{n}-\mathrm{J}-[\mathrm{CRU}]_{m}-\mathrm{EG}_{2}$ have different end-groups, but otherwise multiplication could be applied, the names for the two different end-groups should precede the name for the central non-repeating junction group in the complete name of the polymer. That is to say, when the central non-repeating junction group can function as a multiplying group for CRUs, the nonmultiplying end-groups precede the multiplying group, keeping the multiplier and the multiplying CRU together.

This nomenclature style is recommended because it generally results in greater clarity versus other possibilities. Thus, for the first example shown below, the name $\alpha, \alpha^{\prime}$-(phenylphosphinylidene)- $\omega$-ethoxy$\omega^{\prime}$-hydroxybis[poly(oxyethylene)] is discouraged.

Shown below are two examples of the application of Nomenclature Recommendation 2 combined with the existing nomenclature recommendations. Each example contains two occurrences of an identical CRU connected by one simple non-repeating junction unit and non-identical end-groups.

In some instances in this document, the block copolymer names are provided as synonyms which are named according to previously published IUPAC nomenclature recommendations [3]. Block copolymer nomenclature names block copolymers on the basis of how the structure is drawn. The blocks (CRUs) and junction units are named sequentially from left to right within the written structure and dashes are used for their bonding. The generic style of linear block copolymer nomenclature is poly $\left(\mathrm{CRU}_{1}\right)-\mathrm{X}_{\mathrm{A}}(\mathrm{junction}$ unit $\mathrm{A})-$ poly $\left(\mathrm{CRU}_{2}\right)-\mathrm{X}_{\mathrm{B}}($ junction unit $\mathrm{B})-$ poly $\left(\mathrm{CRU}_{3}\right) \ldots[3]$. This block copolymer nomenclature is usually simple and easy to build and read, but the new nomenclature system developed and recommended in this document is more logical and systematic.

Two examples are shown below:

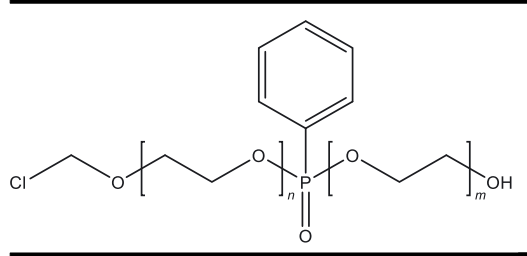

$\omega$-(chloromethoxy)- $\omega^{\prime}$-hydroxy- $\alpha, \alpha^{\prime}$-(phenylphosphoryl)bis[poly(oxyethylene)] Synonym: $\alpha$-(chloromethoxy)- $\omega$-hydroxy[poly(ethyleneoxy)-phenylphosphorylpoly(oxyethylene)]

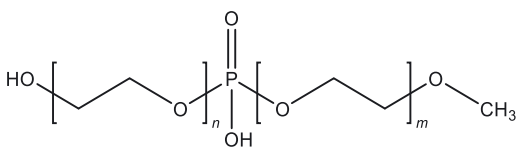

$\omega$-Hydroxy- $\omega^{\prime}$-methoxy- $\alpha, \alpha^{\prime}$-hydroxyphosphorylbis[poly(oxyethylene)] Synonym: $\alpha$-Hydroxy- $\omega$-methoxy[poly(ethyleneoxy)-hydroxyphosphorylpoly(oxyethylene)] 
Extension of the basic concepts delineated above to irregular single-strand polymers of the type repre-

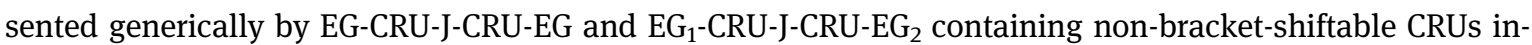
troduces seven new generic types, for which new nomenclature recommendations are given below.

A correctly oriented CRU comprises a parenthesized or bracketed sequence of subunits in which the senior subunit is leftmost [1]. Within this document, the leftmost (senior) subunit is called the "head" of the CRU (the $\alpha$-end) and the other end of the sequence is called the "tail" (the $\omega$-end). For example, in the asymmetrical, non-bracket-shiftable CRU -[O-CO- $\left.\mathrm{CH}_{2}\right]_{n^{-}}$, the senior subunit, oxy, is drawn in the leftmost position, and the methylene subunit is therefore at the tail.

The seven new generic types, in which HT represents a non-bracket-shiftable CRU, are summarized in Table 3.

Table 3: Generic representations of polymers containing two occurrences of an identical, non-bracket-shiftable CRU connected by one simple non-repeating junction unit.

\begin{tabular}{|c|c|c|c|c|}
\hline No. & Generic type & Generic type (abbrev.) & CRU orientation & No. of types of end-groups \\
\hline 1 & EG- $\omega-T H-\alpha-J-\alpha-H T-\omega-E G$ & EG-TH-J-HT-EG & Head-to-head & 1 \\
\hline 2 & $E_{1}-\omega-T H-\alpha-J-\alpha-H T-\omega-E_{2}$ & $\mathrm{EG}_{1}$-TH-J-HT-EG 2 & Head-to-head & 2 \\
\hline 3 & $E G-\alpha-H T-\omega-J-\omega-T H-\alpha-E G$ & EG-HT-J-TH-EG & Tail-to-tail & 1 \\
\hline 4 & $E G_{1}-H T-\omega-J-\omega-T H-\alpha-E G_{2}$ & $\mathrm{EG}_{1}-\mathrm{HT}-\mathrm{J}-\mathrm{TH}-\mathrm{EG}_{2}$ & Tail-to-tail & 2 \\
\hline 5 & $E G-\alpha-H T-\omega-J-\alpha-H T-\omega-E G$ & EG-HT-J-HT-EG & Head-to-tail & 1 \\
\hline 6 & $E_{1}-\alpha-H T-\omega-J-\alpha-H T-\omega-E G_{2}$ & $\mathrm{EG}_{1}-\mathrm{HT}-\mathrm{J}-\mathrm{HT}-\mathrm{EG}_{2}$ & Head-to-tail & 2 \\
\hline 7 & $E_{2}-\alpha-H T-\omega-J-\alpha-H T-\omega-E_{1}$ & $\mathrm{EG}_{2}-\mathrm{HT}-\mathrm{J}-\mathrm{HT}-\mathrm{EG}_{1}$ & Head-to-tail & 2 \\
\hline
\end{tabular}

These seven types are now discussed, and new Nomenclature Recommendations are given for each.

\section{Generic type EG-TH-J-HT-EG (Table 3, Line 1)}

Polymer containing two occurrences of an identical CRU other than a bracket-shiftable polyalkylene glycol in which the CRUs are arranged "head-to-head" and connected by one simple non-repeating junction unit (see Section 2) and the polymer is terminated with identical end-groups.

\section{Nomenclature Recommendation 8}

The nomenclature style recommended for this type is

$\alpha, \alpha$ '-(name of J)bis[ $\omega$-(name of EG)poly(name of CRU)]

\section{Example:}

Name: $\alpha, \alpha$-(ethylene)bis $\{\omega$-methoxypoly[oxy(1-oxoethylene)]\}

$$
\mathrm{CH}_{3} \mathrm{O}-\left[\mathrm{CH}_{2}-\mathrm{CO}-\mathrm{O}\right]_{n}-\mathrm{CH}_{2}-\mathrm{CH}_{2}-\left[\mathrm{O}-\mathrm{CO}-\mathrm{CH}_{2}\right]_{n}-\mathrm{OCH}_{3}
$$

$\alpha$ - and $\omega$-connectives added for clarity:

$$
\mathrm{CH}_{3} \mathrm{O}-\omega^{\prime}-\left[\mathrm{CH}_{2}-\mathrm{CO}-\mathrm{O}\right]_{n}-\alpha^{\prime}-\mathrm{CH}_{2} \mathrm{CH}_{2}-\alpha-\left[\mathrm{O}-\mathrm{CO}-\mathrm{CH}_{2}\right]_{m}-\omega-\mathrm{OCH}_{3}
$$

Note: Nomenclature Recommendation 8 is a simple adaptation of Nomenclature Recommendation 2 applied to non-bracket-shiftable polymers of the type EG-TH-J-HT-EG.

\section{Generic type EG EGH-J-HT-EG $_{2}$ (Table 3, Line 2)}

Polymer containing two occurrences of an identical CRU other than a bracket-shiftable polyalkylene glycol in which the CRUs are arranged "head-to-head" and connected by one simple non-repeating junction unit (see Section 2) and the polymer is terminated with non-identical end-groups $\mathrm{EG}_{1}$ and $\mathrm{EG}_{2}$, where the name of $\mathrm{EG}_{1}$ alphabetizes earlier than the name for $\mathrm{EG}_{2}$. 


\section{Nomenclature Recommendation 9}

The nomenclature style recommended for this type is

$\omega$-(name of $\left.E_{1}\right)-\omega^{\prime}$-(name of $\left.E_{2}\right)-\alpha, \alpha^{\prime}$-(name of J)bis[poly(name of CRU)]

\section{Example:}

Name: $\omega$-ethoxy- $\omega^{\prime}$-methoxy- $\alpha, \alpha$ '-(ethylene)bis\{poly[oxy(1-oxoethylene)]\}

Synonym: $\alpha$-ethoxy- $\omega$-methoxy\{poly[(2-oxoethylene)oxy]-ethylene-poly[oxy(1-oxoethylene)]\}

$$
\mathrm{CH}_{3} \mathrm{CH}_{2} \mathrm{O}-\left[\mathrm{CH}_{2}-\mathrm{CO}-\mathrm{O}\right]_{n}-\mathrm{CH}_{2}-\mathrm{CH}_{2}-\left[\mathrm{O}-\mathrm{CO}-\mathrm{CH}_{2}\right]_{m}-\mathrm{OCH}_{3}
$$

$\alpha$ - and $\omega$-connectives added for clarity:

$$
\mathrm{CH}_{3} \mathrm{CH}_{2} \mathrm{O}-\omega^{\prime}-\left[\mathrm{CH}_{2}-\mathrm{CO}-\mathrm{O}\right]_{n}-\alpha^{\prime}-\mathrm{CH}_{2} \mathrm{CH}_{2}-\alpha-\left[\mathrm{O}-\mathrm{CO}-\mathrm{CH}_{2}\right]_{m}-\omega-\mathrm{OCH}_{3}
$$

\section{Generic type EG-HT-J-TH-EG (Table 3, Line 3)}

Polymer containing two occurrences of an identical CRU other than a bracket-shiftable polyalkylene glycol in which the CRUs are arranged "tail-to-tail" and connected by one simple non-repeating junction unit (see Section 2) and the polymer is terminated with identical end-groups.

\section{Nomenclature Recommendation 10}

The nomenclature style recommended for this type is $\omega, \omega^{\prime}$-(name of J)bis[ $\alpha$-(name of EG)poly(name of CRU)]

\section{Example:}

Name: $\omega, \omega^{\prime}$-sulfonylbis $\{\alpha$-ethylpoly[oxy(1-oxoethylene) $\left.]\right\}$

$$
\mathrm{CH}_{3} \mathrm{CH}_{2}-\left[\mathrm{O}-\mathrm{CO}-\mathrm{CH}_{2}\right]_{n}-\mathrm{SO}_{2}-\left[\mathrm{CH}_{2}-\mathrm{CO}-\mathrm{O}\right]_{m}-\mathrm{CH}_{2} \mathrm{CH}_{3}
$$

$\alpha$ - and $\omega$-connectives added for clarity:

$$
\mathrm{CH}_{3} \mathrm{CH}_{2}-\alpha^{\prime}-\left[\mathrm{O}-\mathrm{CO}-\mathrm{CH}_{2}\right]_{n}-\omega^{\prime}-\mathrm{SO}_{2}-\omega-\left[\mathrm{CH}_{2} \mathrm{CO}-\mathrm{O}\right]_{m}-\alpha-\mathrm{CH}_{2} \mathrm{CH}_{3}
$$

Note: The name for the CRU itself is still written poly[oxy(1-oxoethylene)], rather than its inverse, poly [(2-oxoethylene)oxy]; this is because the sequence of subunits within the CRU is still cited from the $\alpha$-end and not from the $\omega$-end, as described above in Nomenclature Recommendation 3.

\section{Generic type EG EHT-J-TH-EG $_{2}$ (Table 3, Line 4)}

Polymer containing two occurrences of an identical CRU other than a bracket-shiftable polyalkylene glycol in which the CRUs are arranged "tail-to-tail” and connected by one simple non-repeating junction unit (see Section 2) and the polymer is terminated with non-identical end-groups $\mathrm{EG}_{1}$ and $\mathrm{EG}_{2}$, where the name of $\mathrm{EG}_{1}$ alphabetizes earlier than the name for $\mathrm{EG}_{2}$.

\section{Nomenclature Recommendation 11}

The nomenclature style recommended for this type is

$\alpha$-(name of $\left.E G_{1}\right)-\alpha$ '-(name of $\left.E_{2}\right)-\omega, \omega$ '-(name of J)bis[poly(name of CRU)]

\section{Example:}

Name: $\alpha$-ethyl- $\alpha^{\prime}$-methyl- $\omega, \omega^{\prime}$-sulfonylbis\{poly[oxy(1-oxoethylene)]\}

Synonym: $\alpha$-ethyl- $\omega$-methyl\{poly[oxy(1-oxoethylene)]-sulfonyl-poly[(2-oxoethylene)oxy]

$$
\mathrm{CH}_{3} \mathrm{CH}_{2}-\left[\mathrm{O}-\mathrm{CO}-\mathrm{CH}_{2}\right]_{n}-\mathrm{SO}_{2}-\left[\mathrm{CH}_{2} \mathrm{CO}-\mathrm{O}\right]_{m}-\mathrm{CH}_{3}
$$

$\alpha$ - and $\omega$-connectives added for clarity:

$$
\mathrm{CH}_{3} \mathrm{CH}_{2}-\alpha-\left[\mathrm{O}-\mathrm{CO}-\mathrm{CH}_{2}\right]_{n}-\omega-\mathrm{SO}_{2}-\omega^{\prime}-\left[\mathrm{CH}_{2} \mathrm{CO}-\mathrm{O}\right]_{m}-\alpha^{\prime}-\mathrm{CH}_{3}
$$


Note: The name for the CRU itself is still written poly[oxy(1-oxoethylene)], rather than its inverse, poly [(2-oxoethylene)oxy]; this is because the sequence of subunits within the CRU is still cited from the $\alpha$-end and not from the $\omega$-end, as described above in Nomenclature Recommendation 3.

\section{Generic type EG-HT-J-HT-EG (Table 3, Line 5)}

Polymer containing two occurrences of an identical CRU other than a bracket-shiftable polyalkylene glycol in which the CRUs are arranged "head-to-tail" and connected by one simple non-repeating junction unit (see Section 2) and the polymer is terminated with identical end-groups.

\section{Nomenclature Recommendation 12}

The nomenclature style recommended for this type is

$\alpha, \omega^{\prime}$-bis(name of EG)- $\alpha^{\prime}, \omega$-(name of J)bis[poly(name of CRU)]

\section{Example:}

Name: $\alpha, \omega^{\prime}$-disulfo- $\alpha^{\prime}, \omega$-sulfonylbis\{poly[oxy(1-oxoethylene) $\left.]\right\}$

Synonym: $\alpha, \omega$-disulfo\{poly[oxy(1-oxoethylene)]-sulfonyl-poly[oxy(1-oxoethylene)]\}

$$
\mathrm{HO}_{3} \mathrm{~S}-\left[\mathrm{O}-\mathrm{CO}-\mathrm{CH}_{2}\right]_{n}-\mathrm{SO}_{2}-\left[\mathrm{O}-\mathrm{CO}-\mathrm{CH}_{2}\right]_{m}-\mathrm{SO}_{3} \mathrm{H}
$$

$\alpha$ - and $\omega$-connectives added for clarity:

$$
\mathrm{HO}_{3} \mathrm{~S}-\alpha-\left[\mathrm{O}-\mathrm{CO}-\mathrm{CH}_{2}\right]_{n}-\omega-\mathrm{SO}_{2}-\alpha^{\prime}-\left[\mathrm{O}-\mathrm{CO}-\mathrm{CH}_{2}\right]_{m}-\omega^{\prime}-\mathrm{SO}_{3} \mathrm{H}
$$

Note: It is anticipated that in irregular linear polymers of this type, most non-bracket-shiftable CRUs encountered will typically consist of polyamides, polyesters, or polyurethanes. It is therefore unlikely that the two endgroups would receive the same name. Nevertheless, this example is included for completeness. The two examples shown in Lines 6 and 7 in Table 3 are much more commonly encountered.

\section{Generic type EG -HT-J-HT-EG $_{2}$ (Table 3, Line 6)}

Polymer containing two occurrences of an identical CRU other than a bracket-shiftable polyalkylene glycol in which the CRUs are arranged "head-to-tail" and connected by one simple non-repeating junction unit (see Section 2) and the polymer is terminated with non-identical end-groups $\mathrm{EG}_{1}$ and $\mathrm{EG}_{2}$, where the name of $\mathrm{EG}_{1}$ alphabetizes earlier than the name for $\mathrm{EG}_{2}$.

\section{Nomenclature Recommendation 13}

The nomenclature style recommended for this type is

$\alpha$-(name of $\left.\mathrm{EG}_{1}\right)-\omega^{\prime}$-(name of $\left.\mathrm{EG}_{2}\right)-\alpha^{\prime}, \omega$-(name of J)bis[poly(name of CRU)]

\section{Example:}

Name: $\alpha$-ethyl- $\omega^{\prime}$-methoxy- $\alpha^{\prime}, \omega$-sulfonylbis\{poly[oxy(1-oxoethylene)]\}

Synonym: $\alpha$-ethyl- $\omega$-methoxy\{poly[oxy(1-oxoethylene)]-sulfonyl-poly[oxy(1-oxoethylene)]\}

$$
\mathrm{CH}_{3} \mathrm{CH}_{2}-\left[\mathrm{O}-\mathrm{CO}-\mathrm{CH}_{2}\right]_{n}-\mathrm{SO}_{2}-\left[\mathrm{O}-\mathrm{CO}-\mathrm{CH}_{2}\right]_{m}-\mathrm{OCH}_{3}
$$

$\alpha$ - and $\omega$-connectives added for clarity:

$$
\mathrm{CH}_{3} \mathrm{CH}_{2}-\alpha-\left[\mathrm{O}-\mathrm{CO}-\mathrm{CH}_{2}\right]_{n}-\omega-\mathrm{SO}_{2}-\alpha^{\prime}-\left[\mathrm{O}-\mathrm{CO}-\mathrm{CH}_{2}\right]_{m}-\omega^{\prime}-\mathrm{OCH}_{3}
$$

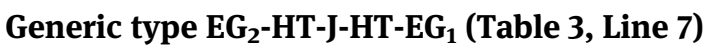

Polymer containing two occurrences of an identical CRU other than a bracket-shiftable polyalkylene glycol in which the CRUs are arranged "head-to-tail" and connected by one simple non-repeating junction unit (see Section 2) and the polymer is terminated with non-identical end-groups $\mathrm{EG}_{1}$ and $\mathrm{EG}_{2}$, where the name of $\mathrm{EG}_{1}$ alphabetizes earlier than the name of $\mathrm{EG}_{2}$. 


\section{Nomenclature Recommendation 14}

The nomenclature style recommended for this type is

$\omega$-(name of $\left.E G_{1}\right)-\alpha^{\prime}-\left(\right.$ name of $\left.E G_{2}\right)-\alpha, \omega^{\prime}$-(name of J)bis[poly(name of CRU)]

\section{Example:}

Name: $\omega$-butoxy- $\alpha^{\prime}$-propyl- $\alpha, \omega^{\prime}$-sulfonylbis\{poly[oxy(1-oxoethylene)]\}

Synonym: $\alpha$-butoxy- $\omega$-propyl\{poly[(2-oxoethylene)oxy]-sulfonyl-poly[(2-oxoethylene)oxy]\}

$$
\mathrm{CH}_{3} \mathrm{CH}_{2} \mathrm{CH}_{2}-\left[\mathrm{O}-\mathrm{CO}-\mathrm{CH}_{2}\right]_{n}-\mathrm{SO}_{2}-\left[\mathrm{O}-\mathrm{CO}-\mathrm{CH}_{2}\right]_{m}-\mathrm{OCH}_{2} \mathrm{CH}_{2} \mathrm{CH}_{2} \mathrm{CH}_{3}
$$

$\alpha$ - and $\omega$-connectives added for clarity:

$$
\mathrm{CH}_{3} \mathrm{CH}_{2} \mathrm{CH}_{2}-\alpha^{\prime}-\left[\mathrm{O}-\mathrm{CO}-\mathrm{CH}_{2}\right]_{n}-\omega^{\prime}-\mathrm{SO}_{2}-\alpha-\left[\mathrm{O}-\mathrm{CO}-\mathrm{CH}_{2}\right]_{m}-\omega-\mathrm{OCH}_{2} \mathrm{CH}_{2} \mathrm{CH}_{2} \mathrm{CH}_{3}
$$

Table 4: Examples of the new nomenclature recommendations applied to polymers other than bracket-shiftable polyalkylene glycols containing one simple central non-repeating junction unit and two identical CRUs.
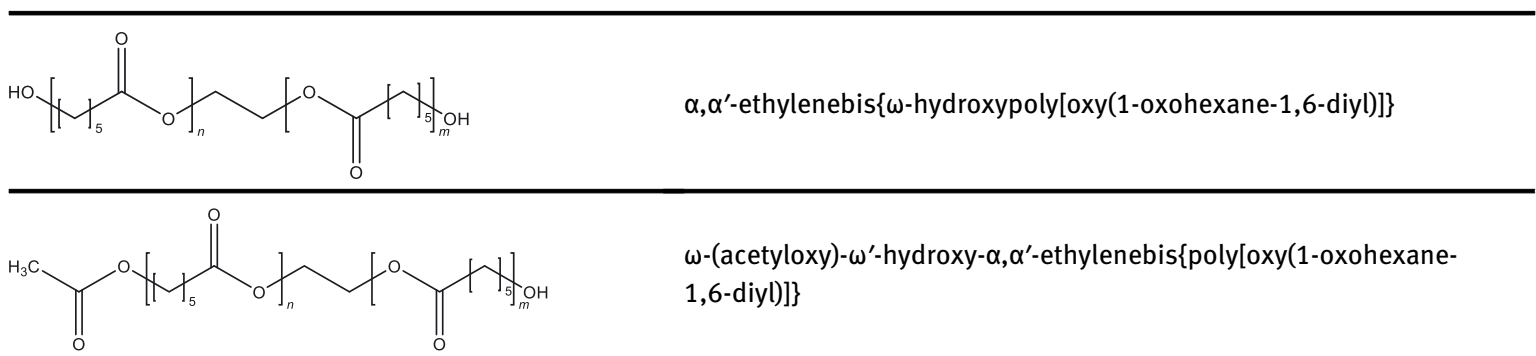

$\omega$-(acetyloxy)- $\omega^{\prime}$-hydroxy- $\alpha, \alpha^{\prime}$-ethylenebis\{poly[oxy(1-oxohexane-

1,6-diyl)]\}

Synonym: $\alpha$-(acetyloxy)- $\omega$-hydroxy\{poly[(6-oxohexane-1,6-diyl)oxy]ethylene-poly[oxy(1-oxohexane-1,6-diyl)]\}

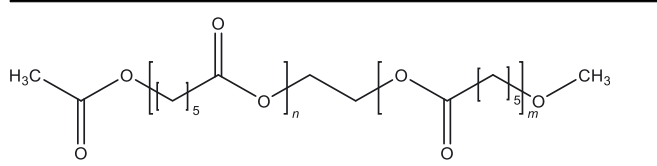

$\omega$-(acetyloxy)- $\omega^{\prime}$-methoxy- $\alpha, \alpha^{\prime}$-ethylenebis $\{$ poly[oxy(1-oxohexane1,6-diyl)]\}

Synonym: $\alpha$-(acetyloxy)- $\omega$-methoxy\{poly[(6-oxohexane-1,6-diyl)oxy]ethylene-poly[oxy(1-oxohexane-1,6-diyl)]\}<smiles>CCC(=O)OCCOC(=O)OCCOC(C)=O</smiles>

$\omega$-(acetyloxy)- $\omega^{\prime}$-(1-oxopropoxy)- $\alpha, \alpha^{\prime}$-ethylenebis\{poly[oxy(1oxohexane-1,6-diyl)]\}

Synonym: $\alpha$-(acetyloxy)- $\omega$-(1-oxopropoxy)\{poly[(6-oxohexane-1,6-diyl) oxy]-ethylene-poly[oxy(1-oxohexane-1,6-diyl)]\}<smiles>COC(=O)CC(=O)OCCC(C)(C)OC(=O)CCO</smiles>

$\omega$-Hydroxy- $\omega^{\prime}$-methoxy- $\alpha, \alpha^{\prime}$-ethylenebis\{poly[oxy(1-oxohexane1,6-diyl)]\}

Synonym: $\alpha$-Methoxy- $\omega$-hydroxy\{poly[(6-oxohexane-1,6-diyl)oxy]ethylene-poly[oxy(1-oxohexane-1,6-diyl)]\}

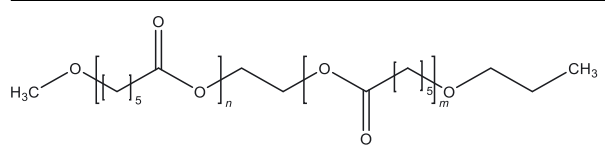

$\omega$-Methoxy- $\omega^{\prime}$-propoxy- $\alpha, \alpha^{\prime}$-ethylenebis $\{$ poly[oxy(1-oxohexane1,6-diyl)]\}

Synonym: $\alpha$-Methoxy- $\omega$-propoxy\{poly[(6-oxohexane-1,6-diyl)oxy]ethylene-poly[oxy(1-oxohexane-1,6-diyl)]\}

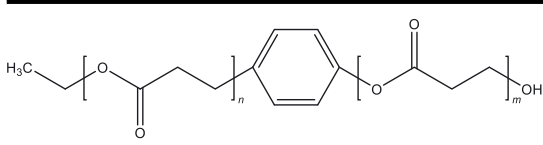

$\alpha$-Ethyl- $\omega^{\prime}$-hydroxy- $\alpha^{\prime}, \omega-1,4$-phenylenebis\{poly[oxy(1-oxopropane1,3-diyl)]\} 
Table 4: (continued)

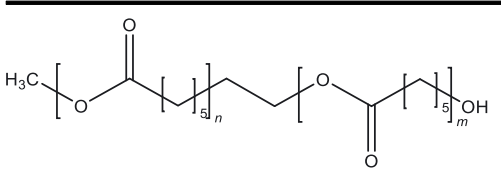

$\omega$-Hydroxy- $\alpha^{\prime}$-methyl- $\alpha, \omega^{\prime}$-ethylenebis\{poly[oxy(1-oxohexane-1,6-diyl)]\}

Synonym: $\alpha$-Hydroxy- $\omega$-methyl\{poly[(6-oxohexane-1,6-diyl)oxy]-

ethylene-poly[(6-oxohexane-1,6-diyl)oxy]\} or

$\alpha$-methyl- $\omega$-hydroxy\{poly[oxy(1-oxohexane-1,6-diyl)]-ethylene-poly [oxy(1-oxohexane-1,6-diyl)]\}

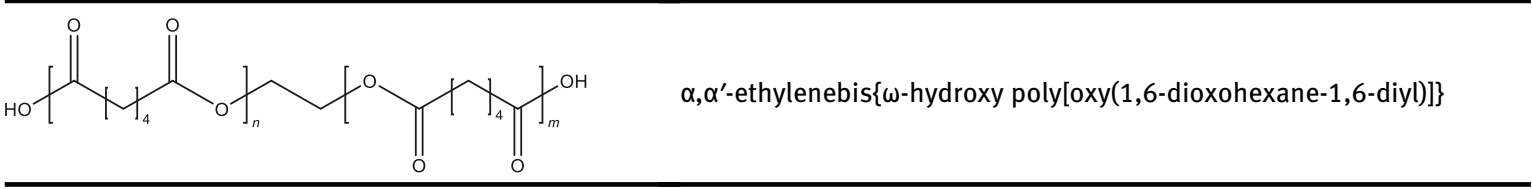<smiles>COC(=O)CNC(=O)OCCCOC(=O)CCC(C)C(=O)OC</smiles><smiles>CCOC(=O)NC(=O)OCCCOC(=O)OCCC(=O)OC</smiles>

$\omega$-Hydroxy- $\omega^{\prime}$-methoxy- $\alpha, \alpha^{\prime}$-ethylenebis\{poly[oxy(1,6-dioxohexane1,6-diyl)]\}

Synonym: $\alpha$-Methoxy- $\omega$-hydroxy\{poly[(1,6-dioxohexane-1,6-diyl)oxy]ethylene-poly[oxy(1,6-dioxohexane-1,6-diyl)]\}

$\omega$-Ethoxy- $\omega^{\prime}$-methoxy- $\alpha, \alpha^{\prime}$-ethylenebis\{poly[oxy(1,6-dioxohexane1,6-diyl)]\}

Synonym: $\alpha$-Ethoxy- $\omega$-methoxy\{poly[(1,6-dioxohexane-1,6-diyl)oxy]ethylene-poly[oxy(1,6-dioxohexane-1,6-diyl)]\}

\section{SCB-6.1.2 Polymers with two blocks of CRU connected by complex junction unit}

In this category, eight new generic types, in which AG represents a bracket-shiftable CRU such as a polyalkylene glycol, HT represents a non-bracket-shiftable CRU, Jc represents a non-repeating complex junction unit, EG represents an end-group, and $\mathrm{EG}_{1}$ and $\mathrm{EG}_{2}$ represent different end-groups, are summarized in Table 5.

Table 5: Generic representations of polymers containing two occurrences of an identical CRU connected by a single nonrepeating complex junction unit.

\begin{tabular}{llllr}
\hline No. & Generic type & Generic type (abbrev.) & CRU orientation & No. of types of end-groups \\
\hline 1 & $E G-\omega-A G-\alpha-J c-\alpha-A G-\omega-E G$ & $E G-A G-J c-A G-E G$ & Head-to-head & 1 \\
2 & $E G_{1}-\omega-A G-\alpha-J c-\alpha-A G-\omega-E G_{2}$ & $E G_{1}-A G-J c-A G-E G_{2}$ & Head-to-head & 2 \\
3 & $E G-\omega-T H-\alpha-J c-\alpha-H T-\omega-E G$ & $E G-T H-J c-H T-E G$ & Head-to-head & 1 \\
4 & $E_{1}-\omega-T H-\alpha-J c-\alpha-H T-\omega-E G_{2}$ & $E G_{1}-T H-J c-H T-E G_{2}$ & Head-to-head & 2 \\
5 & $E G-\alpha-H T-\omega-J c-\omega-T H-\alpha-E G$ & $E G-H T-J c-T H-E G$ & Tail-to-tail & 1 \\
6 & $E_{1}-H T-\omega-J c-\omega-T H-\alpha-E G_{2}$ & $E G_{1}-H T-J c-T H-E G_{2}$ & Tail-to-tail & 2 \\
7 & $E_{-}-\alpha-H T-\omega-J c-\alpha-H T-\omega-E G$ & $E G-H T-J c-H T-E G$ & Head-to-tail & 1 \\
8 & $E_{1}-\alpha-H T-\omega-J c-\alpha-H T-\omega-E G_{2}$ & $E G_{1}-H T-J c-H T-E G_{2}$ & Head-to-tail & 2 \\
\hline
\end{tabular}

\section{Nomenclature Recommendation 15}

This recommendation details the procedure for the selection of the preferred name for each of the eight generic types shown in Table 5 . The multistep procedure is given below.

(1) For the generic type shown on Line 1 of Table 5, select the preferred name according to Steps 1-5.

(2) For the other seven generic types in Table 5, select the preferred name according to Steps 2-5.

(1) In accordance with Nomenclature Recommendation 2 given above, bracket-shift the parentheses or brackets of both CRUs inward toward the complex junction Jc. 
(2) Arbitrarily select one of the two CRUs as the senior CRU and treat all other moieties and subunits as $\alpha$ and $\omega$-end-groups.

(3) Based on the CRU selected in Step 2, name the complete polymer. One end-group will contain the other CRU embedded within it.

(4) Now select the other CRU as the senior CRU, name the complete polymer, and compare the name with the one generated in Step 3.

(5) Compare the two names generated; the name that alphabetizes earlier is selected as the preferred name.

The procedure is illustrated in the following examples.

Example of generic type EG-AG-Jc-AG-EG (Table 5, Line 1):

$$
\mathrm{HO}-\left[\mathrm{CH}_{2}-\mathrm{CH}_{2}-\mathrm{O}\right]_{n}-\mathrm{CH}_{2}-\mathrm{SO}_{2}-\left[\mathrm{O}-\mathrm{CH}_{2}-\mathrm{CH}_{2}\right]_{m}-\mathrm{OH}
$$

Arbitrary selection of one of the CRUs as "senior CRU” gives:

$$
\begin{gathered}
\mathrm{HO}-\left[\mathrm{CH}_{2}-\mathrm{CH}_{2}-\mathrm{O}\right]_{n}-\mathrm{CH}_{2}-\mathrm{SO}_{2}-\left[\mathrm{O}-\mathrm{CH}_{2}-\mathrm{CH}_{2}\right]_{m}-\mathrm{OH} \\
\text { a-end-group }
\end{gathered}
$$

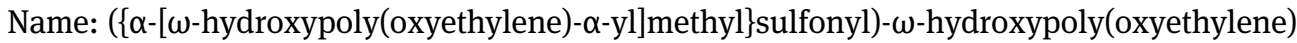

Selection of the other CRU as the "senior CRU" gives:

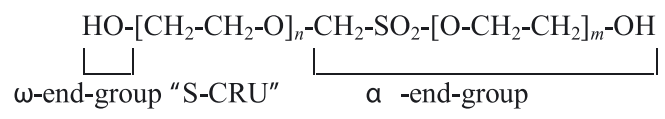

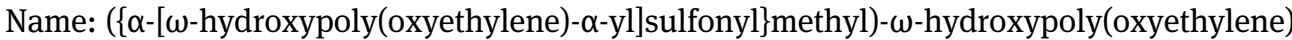

The preferred name is therefore $(\{\alpha-[\omega$-hydroxypoly(oxyethylene)- $\alpha$-yl $]$ methyl $\}$ sulfonyl)- $\omega$-hydroxypoly(oxyethylene).

Synonym: $\alpha, \omega$-dihydroxy[poly(ethyleneoxy)-methylenesulfonyl-poly(oxyethylene)]

Note: Except for the complex junction Jc, the generic type EG-AG-Jc-AG-EG (Table 5, Line 1) is seen to be laterally symmetrical. Therefore, the preferred name for the polymer will depend on the alphabetization of Jc.

Example of generic type $\mathrm{EG}_{1}-\mathrm{AG}-\mathrm{Jc}-\mathrm{AG}-\mathrm{EG}_{2}$ (Table 5, Line 2):

$$
\mathrm{CH}_{2} \mathrm{C} 1-\mathrm{O}-\left[\mathrm{CH}_{2}-\mathrm{CH}_{2}-\mathrm{O}\right]_{n}-\mathrm{CH}_{2}-\mathrm{SO}_{2}-\left[\mathrm{O}-\mathrm{CH}_{2}-\mathrm{CH}_{2}\right]_{m}-\mathrm{OCH}_{3}
$$

Arbitrary selection of one of the CRUs as the "senior CRU" gives:

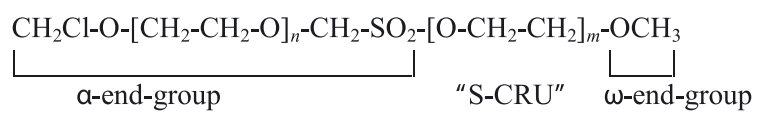

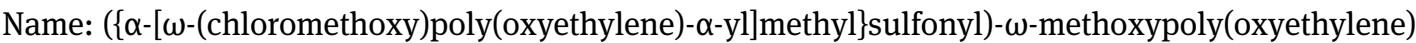

Selection of the other CRU as the "senior CRU" gives:

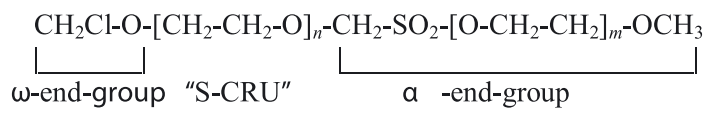

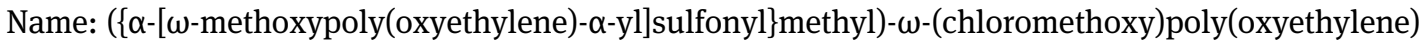

The alphabetically earlier and therefore preferred name is

$(\{\alpha-[\omega-($ chloromethoxy)poly(oxyethylene) $-\alpha-y l]$ methyl $\}$ sulfonyl $)-\omega-$ methoxypoly (oxyethylene).

Synonym: $\alpha$-(chloromethoxy)- $\omega$-methoxy-[poly(ethyleneoxy)-methylenesulfonyl-poly(oxyethylene)] 
Note: The difference between this generic type and the one shown in Line 1 of Table 5 is that the polymer is not laterally symmetrical. The preferred name for the polymer will depend on the names of the two endgroups and not on the alphabetization of Jc.

Example of generic type EG-TH-Jc-HT-EG (Table 5, Line 3):

$$
\left(\mathrm{CH}_{3}\right)_{2} \mathrm{~N}-\left[\mathrm{CH}_{2}-\mathrm{CO}-\mathrm{NH}\right]_{n}-\mathrm{CH}_{2}-\mathrm{SO}_{2}-\left[\mathrm{NH}-\mathrm{CO}-\mathrm{CH}_{2}\right]_{m}-\mathrm{N}\left(\mathrm{CH}_{3}\right)_{2}
$$

Arbitrary selection of one of the CRUs as the "senior CRU” gives:

$$
\left.\right|_{\text {a-end-group }} ^{\left(\mathrm{CH}_{3}\right)_{2} \mathrm{~N}-\left[\mathrm{CH}_{2}-\mathrm{CO}-\mathrm{NH}\right]_{n}-\mathrm{CO}-\mathrm{SO}_{2}-\left[\mathrm{NH}-\mathrm{CO}-\mathrm{CH}_{2}\right]_{m}-\mathrm{N}\left(\mathrm{CH}_{3}\right)_{2}}
$$

Name: [( $\alpha$-\{ $\omega$-(dimethylamino)poly[azanediyl(1-oxoethylene)]- $\alpha$-yl $\}$ carbonyl)sulfonyl]- $\omega$-(dimethylamino)poly [azanediyl(1-oxoethylene)]

Selection of the other CRU as the "senior CRU” gives:

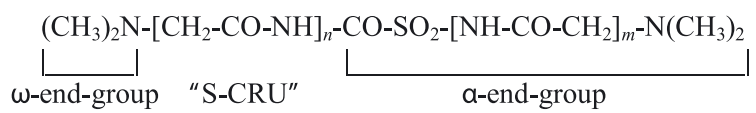

Name: [( $\alpha$ - $\{\omega$-(dimethylamino)poly[azanediyl(1-oxoethylene)]- $\alpha$-yl $\}$ sulfonyl)carbonyl]- $\omega$-(dimethylamino)poly [azanediyl(1-oxoethylene)]

The alphabetically earlier and therefore preferred name is

$$
[(\alpha-\{\omega-(\text { dimethylamino)poly[azanediyl(1-oxoethylene })]-\alpha-y l\} \text { carbonyl }) \text { sulfonyl }]-\omega
$$$$
\text { - (dimethylamino)poly[azanediyl(1-oxoethylene)] }
$$

Synonym: $\alpha, \omega$-(dimethylamino)\{poly[(2-oxoethylene)azanediyl]-carbonylsulfonyl-poly[azanediyl(1-oxoethylene)]\}

Note: Except for the complex junction Jc, the generic type EG-TH-Jc-HT-EG (Table 5, Line 3) is seen to be laterally symmetrical. Therefore, the preferred name for the polymer will depend on the alphabetization of Jc.

Table 6 lists further examples of polymers containing two occurrences of an identical CRU connected by a complex non-repeating junction unit. The preferred names are given beneath each example. In each case, the CRU selected as the "senior CRU”, i.e., the one that leads to the preferred name is underlined.

Table 6: Further examples of irregular linear, single-strand polymers containing two identical CRUs and a complex non-repeating junction unit.

No. Structure, underlined senior CRU, and preferred polymer name

1

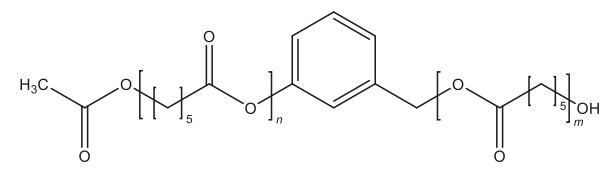

2

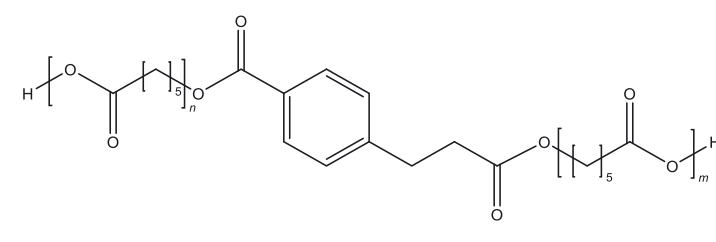

Name: $\alpha-[(3-\{\omega$-(acetyloxy)poly[oxy(1-oxohexane-1,6-diyl)] $\alpha$-yl\}phenyl)methyl]- $\omega$-hydroxypoly[oxy(1-oxohexane1,6-diyl)]

Synonym: $\alpha$-(acetyloxy)- $\omega$-hydroxy\{poly(6-oxohexane1,6-diyl)oxy]-(1,3-phenylene)methylene-poly[oxy(1-oxohexane-1,6-diyl)]\}

Name: $\alpha$-Hydro- $\omega-[(3-\{4-[(\{\alpha-h y d r o p o l y[0 x y(1-o x o h e x a n e-$ 1,6-diyl)]- $\omega$-yl\}oxy)carbonyl]phenyl\}propanoyl)oxy]poly [oxy(1-oxohexane-1,6-diyl)]

Synonym: $\alpha, \omega$-dihydro\{poly[oxy(1-oxohexane-1,6-diyl)]oxycarbonyl(1,4-phenylene)(3-oxopropane-1,3-diyl)oxy-poly [(6-oxohexane-1,6-diyl)oxy]\} 
Table 6: (continued)

No. Structure, underlined senior CRU, and preferred polymer name
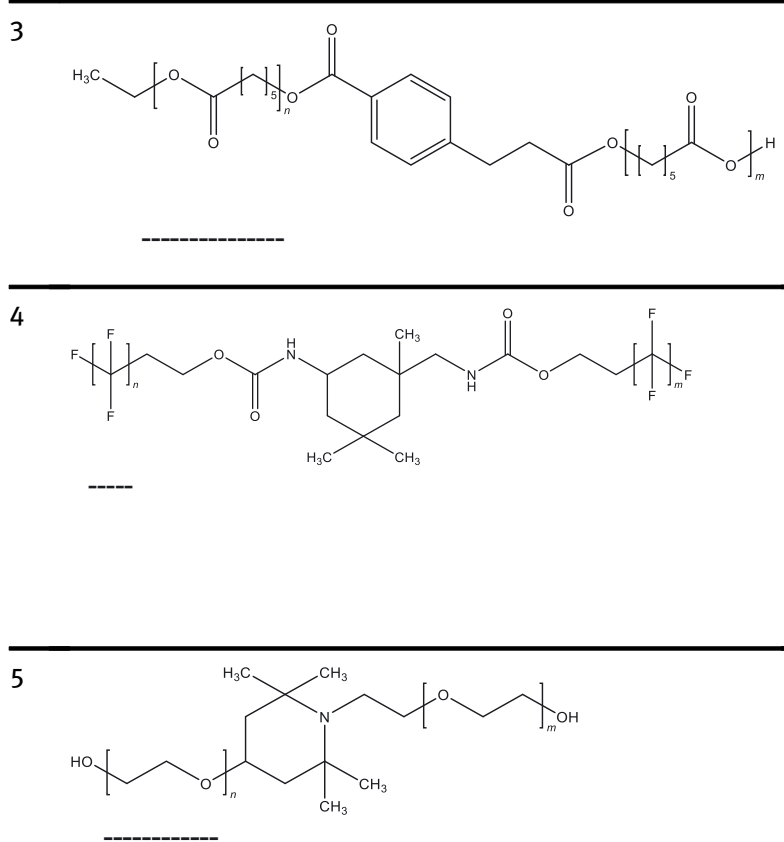

Name: $\alpha$-Ethyl- $\omega-(\{4-[3-(\{\alpha-h y d r o p o l y[o x y(1-o x o h e x a n e-$ 1,6-diyl)]- $\omega$-yl\}oxy)-3-oxopropyl]benzoyl\}oxy)poly[oxy(1-oxohexane-1,6-diyl)]

Synonym: $\alpha$-Ethyl- $\omega$-hydro\{poly[oxy(1-oxohexane-1,6-diyl)]oxycarbonyl(1,4-phenylene)(3-oxopropane-1,3-diyl)oxy-poly [(6-oxohexane-1,6-diyl)oxy]\}

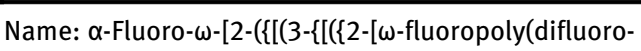
methylene)- $\alpha$-yl]ethoxy\}carbonyl)amino]methyl\}3,5,5-trimethylcyclohexyl)amino]carbonyl\}oxy)ethyl]poly(difluoromethylene)

Synonym: $\alpha, \omega$-difluoro[poly(difluoromethylene)ethyleneoxycarbonylazanediyl(3,5,5-trimethylcyclohexane1,3-diyl)methyleneazanediylcarbonyloxyethylenepoly(difluoromethylene)]

Name: $\alpha-(1-\{2-[\omega$-hydroxypoly(oxyethylene)- $\alpha$-yl]ethyl $\}$ 2,2,6,6-tetramethylpiperidin-4-yl)- $\omega$-hydroxypoly(oxyethylene)

Synonym: $\alpha, \omega$-dihydroxy\{poly(ethyleneoxy)-(2,2,6,6-tetramethylpiperidin-4,1-diyl)ethylene-poly(oxyethylene)]

6

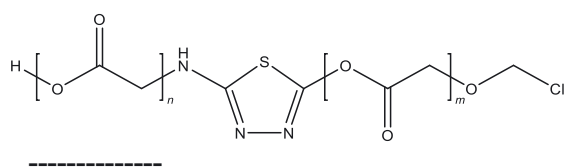

Name: $\alpha$-Hydro- $\omega-[(5-\{\omega$-(chloromethoxy)poly[oxy(1-oxoethylene)]- $\alpha$-yl\}-1,3,4-thiadiazol-2-yl)amino]poly[oxy(1-oxoethylene)]

Synonym: $\alpha$-chloromethoxy- $\omega$-hydro\{poly[(2-oxoethylene) oxy]-(1,3,4-thiadiazol-2,4-diyl)azanediyl-poly [2-oxoethylene)oxy]

7

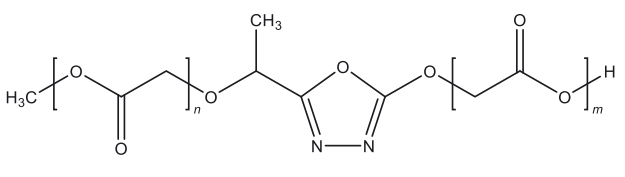
Name: $\alpha$-Hydro- $\omega-(\{5-[1-(\{\alpha-$ methylpoly[oxy(1-oxoethylene $)]-\omega-y l\}$ oxy)ethyl]-1,3,4-oxadiazol-2-yl\}oxy)poly[oxy(1-oxoethylene)]

Synonym: $\alpha$-Hydro- $\omega$-methyl\{poly[oxy(1-oxoethylene)]oxy(1,3,4-oxadiazol-2,4-diyl)ethylideneoxy-poly[(2-oxoethylene) oxy]\}

\section{SCB-6.2 Linear, single-strand polymers containing three blocks of an identical CRU}

The second type of polymer is a linear, single-strand one with three blocks of identical CRUs. It can be represented generically as $\mathrm{EG}_{1}-[\mathrm{CRU}]_{n}-\mathrm{J}_{1}-[\mathrm{CRU}]_{m}-\mathrm{J}_{2}-[\mathrm{CRU}]_{p}-\mathrm{EG}_{2}$, in which $\mathrm{EG}_{1}$ and $\mathrm{EG}_{2}$ are end-groups, $\mathrm{CRU}$ is a constitutional repeating unit, and $\mathrm{J}_{1}$ and $\mathrm{J}_{2}$ are simple or complex non-repeating junction units.

There are three basic methods for the creation of a nomenclature style.

- Method 1. Temporarily designate each of the CRUs in turn as the senior CRU, relegate all other moieties to the roles of end-groups, generate all possible names, and then select the name that alphabetizes earliest.

- Method 2. Temporarily designate one of the two outer CRUs as the senior CRU, relegate all other moieties to the roles of end-groups, and generate the name for the complete polymer. Repeat the process with the other outer CRU temporarily designated as the senior CRU. Select as the final name whichever alphabetizes earlier.

- Method 3. Designate the central CRU as the senior CRU, relegate all other moieties to the roles of endgroups, and generate the name for the complete polymer. 
Even without specific examples to illustrate these three approaches, it should be evident that Method 3 is the simplest and quickest to apply because it involves fewer steps. Even if each of the CRUs is bracket-shiftable, Method 3 still requires the generation of only two names, from which the one that alphabetizes earlier should be selected as the final polymer name. In contrast, the use of Method 1 or Method 2 will generate more names than two, which can become tedious and time-consuming.

Methods 1 and 2 are therefore rejected in favor of Method 3, the steps for which are detailed below as a new nomenclature recommendation.

\section{Nomenclature Recommendation 16}

This recommendation details the procedure for selection of the preferred name for the generic type $\mathrm{EG}_{1^{-}}$

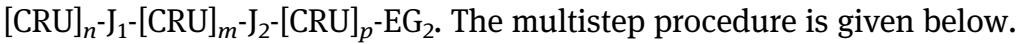

- When the polymer contains three bracket-shiftable CRUs, select the preferred name according to Steps 1-4 below.

- When the polymer contains three non-bracket-shiftable CRUs, select the preferred name according to Steps 1 and 4 below.

- Step 1. Designate the central CRU as the senior CRU.

- Step 2. For polymers containing three bracket-shiftable CRUs, bracket-shift the two outer CRUs toward the central CRU.

- Step 3. For polymers containing three bracket-shiftable CRUs, bracket-shift the parentheses or brackets of the central CRU toward whichever of the two end-groups alphabetizes earlier. If the end-groups are identical or unspecified, bracket-shift the parentheses or brackets of the central CRU toward whichever of the two non-repeating junction units alphabetize earlier.

- Step 4. Name the complete polymer. Each of the two end-groups will contain a CRU embedded within it.

The procedure is illustrated in the following examples.

Example 5.2.1. Linear, single-strand polymer containing three bracket-shiftable CRUs and non-identical endgroups:

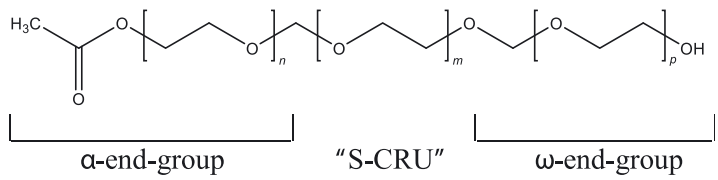

Rationale:

End-group (acetyloxy) alphabetizes earlier than hydroxy; central CRU is therefore bracket-shifted toward the (acetyloxy) end-group, as shown.

The other two CRUs are bracket-shifted toward the central CRU.

Name: $\alpha$ - $\{[\omega$-(acetyloxy)poly(oxyethylene)- $\alpha$-yl $]$ methyl $\}-\omega$ - $\{[\omega$-hydroxypoly(oxyethylene)- $\alpha$-yl $]$ methoxy $\}$ poly (oxyethylene)

Synonym: $\alpha$-(acetyloxy)- $\omega$-hydroxy[poly(ethyleneoxy)-methylene-poly(oxyethylene)-oxymethylene-poly (oxyethylene)]

Example 5.2.2. Linear, single-strand polymer containing three bracket-shiftable CRUs and identical end groups:

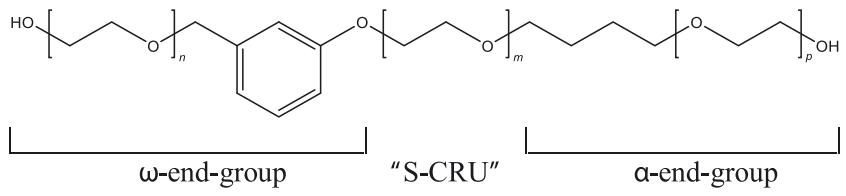


Rationale:

End-groups are identical; central CRU is therefore bracket-shifted toward the non-repeating junction unit that alphabetizes earlier, as shown - butyl versus (methylphenoxy).

The other two CRUs are bracket-shifted toward the central CRU.

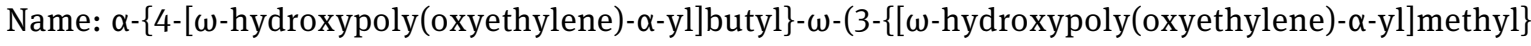
phenoxy)poly(oxyethylene)

Synonym: $\alpha, \omega$-dihydroxy[poly(ethyleneoxy)-methylene(1,3-phenylene)oxy-poly(ethyleneoxy)-(butane-1,4-diyl)poly(oxyethylene)]

Example 5.2.3. Linear, single-strand polymer containing three bracket-shiftable CRUs and unspecified endgroups:

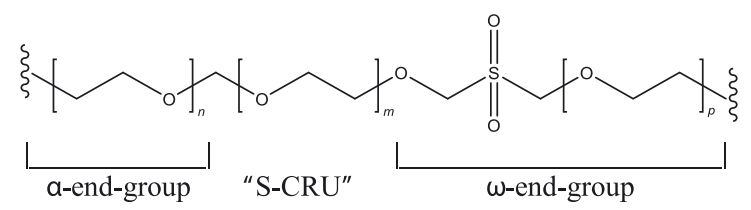

Rationale:

End-groups are unspecified; central CRU is therefore bracket-shifted toward the non-repeating junction unit that alphabetizes earlier, as shown - methyl versus (methylsulfonylmethoxy).

The other two CRUs are bracket-shifted toward the central CRU.

Name: $\alpha-\{2$-[poly(oxyethylene)- $\alpha$-yl]methyl\}- $\omega$-[(\{[poly(oxyethylene)- $\alpha$-yl]methyl $\}$ sulfonyl)methoxy]poly (oxyethylene)

Synonym: poly(ethyleneoxy)-methylene-poly(oxyethylene)-oxymethylenesulfonylmethylene-poly (oxyethylene)

Example 5.2.4. Linear, single-strand polymer containing three non-bracket-shiftable CRUs and non-identical end-groups:

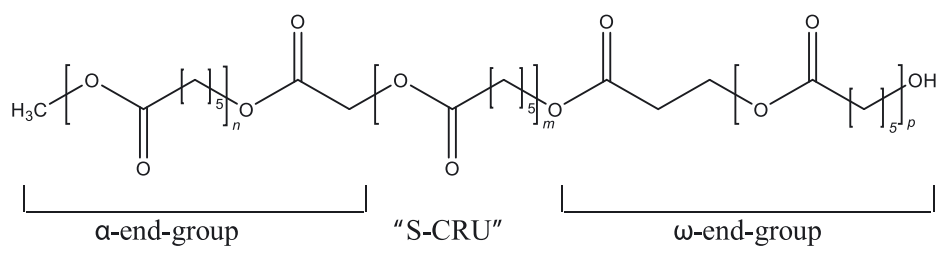

Rationale:

Since the CRUs are not bracket-shiftable, alternative names for end-groups are not possible; hence, only one final polymer name can be generated according to the recommendations.

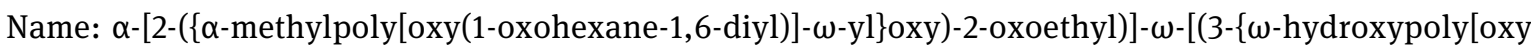
(1-oxohexane-1,6-diyl)]- $\alpha$-yl $\}$ propanoyl)oxy]poly[oxy(1-oxohexane-1,6-diyl)]

Synonym: $\alpha$-methyl- $\omega$-hydroxy\{poly[oxy(1-oxohexane-1,6-diyl)]-oxy(1-oxoethylene)-poly[oxy(1-oxohexane1,6-diyl)]-oxy(1-oxopropane-1,3-diyl)-poly[oxy(1-oxohexane-1,6-diyl)]\}

This document excludes detailed procedures for naming linear, single-strand polymers containing four or more occurrences of an identical CRU. The general procedures recommended are as follows:

- For irregular linear, single-strand polymers containing an odd number of identical CRUs, select the central CRU as the senior CRU and follow the procedure given for irregular linear, single-strand polymers containing three occurrences of an identical CRU.

- For irregular linear, single-strand polymers containing an even number of identical CRUs, temporarily designate, in turn, each of the two innermost CRUs as the senior CRU, relegate all other moieties to the 
roles of end-groups, and generate names for the complete polymer. From the two names generated, select, as the preferred name, the one that alphabetizes earlier.

\section{SCB-6.3 Star-type polymers containing three or more blocks of an identical CRU}

The third type of polymer is a star type with three or more identical blocks of CRUs connected to a central nonrepeating junction unit. It can be represented, for example, as

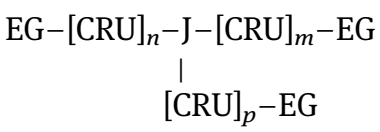

or<smiles>CCCCC(CCC)I(CC)(CCC)(CCC)C(CC)CC</smiles>

etc., in which EG is an end-group (the end-groups may be all identical, partially identical, all different, etc.) and $J$ is a complex non-repeating junction unit.

Naming of these polymers is more difficult than for the linear types of polymers; particularly, if the endgroups are not identical, the central non-repeating junction unit is branched in such a way that it is unnamable as a complete subunit or the environment for each CRU is not identical.

The recommended approach is to designate as many occurrences as possible of the CRU as equal senior CRUs; other occurrences of CRUs and any substituents are designated as subordinate.

Note: Two or more identical CRUs can be considered to be equal senior CRUs when they are in identical environments. An environment in this definition means the connectivities to adjacent subunits or subunit strings (sequences) that extend from the connection bond of the CRU closer (closest) to the complete nonrepeating junction unit as far as and including the complete non-repeating junction unit. The end-groups may be identical or different.

Selection of which occurrences of the CRU to designate as equal senior CRUs usually depends on the structure of the complex non-repeating junction unit that connects to all occurrences of the CRU.

Examples of two or more CRUs in equal environments:

$$
\mathrm{HO}-\left[\mathrm{CH}_{2} \mathrm{CH}_{2} \mathrm{O}\right]_{n}-\left(\mathrm{CH}_{2}\right)_{3}-\left[\mathrm{OCH}_{2} \mathrm{CH}_{2}\right]_{m}-\mathrm{OH}
$$

[Rationale: symmetrical simple non-repeating junction unit]

$$
\mathrm{CH}_{3} \mathrm{O}-\left[\mathrm{CH}_{2} \mathrm{CH}_{2} \mathrm{O}\right]_{n}-\mathrm{CO}\left(\mathrm{CH}_{2}\right)_{4} \mathrm{CO}-\left[\mathrm{OCH}_{2} \mathrm{CH}_{2}\right]_{m}-\mathrm{OCH}_{3}
$$

[Rationale: symmetrical simple non-repeating junction unit]

$$
\mathrm{HO}-\left[\mathrm{CH}_{2} \mathrm{CH}_{2} \mathrm{O}\right]_{n}-\left(\mathrm{CH}_{2}\right)_{6}-\left[\mathrm{OCH}_{2} \mathrm{CH}_{2}\right]_{m}-\mathrm{OCH}_{3}
$$

[Rationale: symmetrical simple non-repeating junction unit; the two CRUs are perceived as equal senior CRUs even though the presence of two different end-groups affects the nomenclature] 


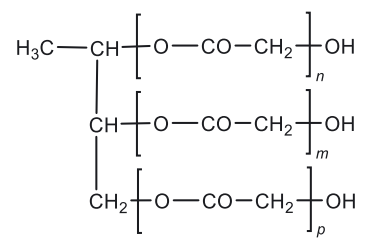

[Rationale: simple non-repeating junction units may be substituted symmetrically, asymmetrically, or both]

Table 4 above shows other examples of polymers with two or more CRUs and identical or different endgroups that can be classified as equal senior CRUs.

Examples of two or more CRUs in different environments:

$$
\mathrm{HO}-\left[\mathrm{CH}_{2} \mathrm{CH}_{2} \mathrm{O}\right]_{n}-\mathrm{CH}_{2} \mathrm{SO}_{2}-\left[\mathrm{OCH}_{2} \mathrm{CH}_{2}\right]_{m}-\mathrm{OH}
$$

[Rationale: asymmetrical complex non-repeating junction unit precludes classification of the two CRUs as equal senior CRUs. Whether end-groups are identical or different is immaterial.]

$$
\mathrm{HO}-\left[\mathrm{CH}_{2} \mathrm{CH}_{2} \mathrm{O}\right]_{n}-\mathrm{CH}_{2} \mathrm{SO}_{2}-\left[\mathrm{OCH}_{2} \mathrm{CH}_{2}\right]_{m}-\mathrm{OCH}_{3}
$$

[Rationale: asymmetrical complex non-repeating junction unit precludes classification of the two CRUs as equal senior CRUs. Whether end-groups are identical or different is immaterial.]

Table 6 above shows other examples of polymers with two or more CRUs that cannot be classified as equal senior CRUs because they are in different environments.

An essential factor to remember in the generation of a recommended name for the polymer is that all possibilities involving equal senior CRUs must be considered. If this results in the generation of more than one name, whichever of the names thus generated alphabetize the earliest becomes the recommended name. The size per se of the central non-repeating junction unit has no influence on the final name, although its name certainly may and often does.

\section{Nomenclature Recommendation 17}

This recommendation details the procedure for the selection of the preferred name for the two branched generic types shown above.

- Step 1. Bracket-shift all bracket-shiftable CRUs toward the central non-repeating junction unit.

- Step 2. Identify the maximum number of CRUs in identical environments; take end-groups into account see Note 2 below.

- Step 3. Designate as many occurrences as possible of CRUs in identical environments as equal senior CRUs. Take into account the orientation of each CRU, e.g., head-to-head or head-to-tail, with respect to the other CRUs and connectivity to other subunits, especially remote end-groups.

- Step 4. Designate the other CRU(s) as subordinate moieties.

- Step 5. Identify the subunits of the central non-repeating junction unit that lie on a direct path between the equal senior CRUs; any remaining subunits will become components of substituents.

- Step 6. Generate an intermediate name that includes all of the CRUs identified in Step 2 and the portion of the central non-repeating junction unit identified in Step 5. Include names of end-groups if present.

- Step 7. If all subunits in the complete polymer have been included in Step 6, then the intermediate name becomes the final name. If additional subunits remain, proceed to Step 8.

- Step 8. Regard all remaining subunits as substituents and generate names for them; attach them to the intermediate name generated in Step 6. The resulting name is the preferred name for the complete polymer.

Note 1: Even if all occurrences of the CRU are in identical environments, it may still not be possible to treat all of them as equal senior CRUs because the central non-repeating junction unit may be branched in such a way that it cannot be named as a simple subunit. For these situations, as many occurrences of the CRU as 
possible are treated as equal senior CRUs; the others are designated as subordinate and become components within substituents.

Note 2: It is recommended that, wherever possible, end-groups should be included in the consideration of which CRUs are in equal environments. Thus, for polymers of the type

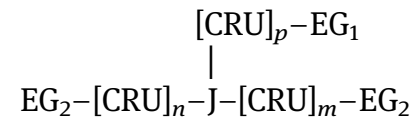

and

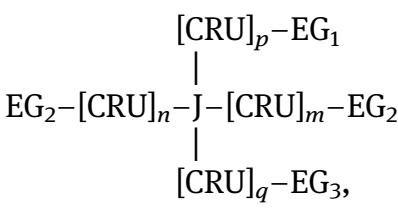

the two CRUs connected to the end-group moieties $-\mathrm{EG}_{2}$ should be designated as equal senior CRUs, even if this results in a name that, out of all possible names, does not alphabetize earliest. The reason is that it simplifies the naming process. See Examples 4 and 5 in Table 7 below.

Note 3: For some polymers, especially those in which no two end-groups are the same, it may be possible to generate several intermediate names. From the intermediate names generated, select the one that alphabetizes earliest as the preferred name. See Example 6 in Table 7 below.

The procedure is illustrated in the examples below. The first two examples demonstrate the application of the steps of Nomenclature Recommendation 16 to compounds already well-known in the literature, and the other examples in this section demonstrate application to homologues.

Example 5.3.1. Three-arm star polymer with three identical bracket-shiftable CRUs, a simple junction unit, and three identical end-groups

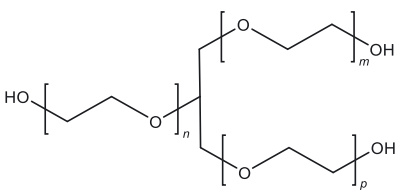

Rationale:

All three CRUs are bracket-shifted toward the central non-repeating junction unit.

All three CRUs are deemed to be in an identical environment because each is connected directly to the central non-repeating junction unit propane-1,2,3-triyl, which has a unitary name and is therefore simple.

Name: $\alpha, \alpha^{\prime}, \alpha$ '-propane-1,2,3-triyltris[ $\omega$-hydroxypoly(oxyethylene)]

Example 5.3.2. Four-arm star polymer with four identical bracket-shiftable CRUs, a complex junction unit, and four identical end-groups

Rationale:

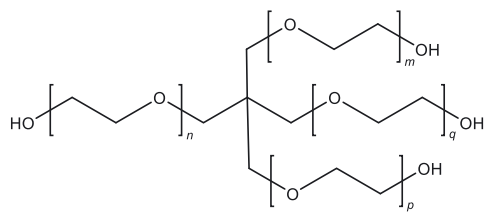

All four CRUs are bracket-shifted toward the central non-repeating junction unit.

Since the junction unit is generated from the branched substance 2,2-bis(hydroxymethyl)propane-1,3-diol, it is also branched and therefore it is complex. The "parent" for this compound, propane-1,3-diol, cites only two 
of the four hydroxy groups, which means that the other moieties are treated as substituents. Likewise, the "parent" component of the final name for the complete polymer can cite only two CRUs; the other two have to be components of substituents.

Name: $\alpha, \alpha^{\prime}-(2,2-$-bis $\{[\omega$-hydroxypoly(oxyethylene)- $\alpha$-yl $]$ methyl $\}$ propane-1,3-diyl)bis $[\omega$-hydroxypoly(oxyethylene)]

Synonym: $\alpha, \alpha^{\prime}, \alpha$ ", $\alpha ”$ '-(methanetetrayltetramethylene)tetrakis[ $\omega$-hydroxypoly(oxyethylene)]

Example 5.3.3. Three-arm star polymer with three identical bracket-shiftable CRUs, a simple junction unit, and three identical end-groups<smiles>CCC(COCCO)(COCCO)OCCO</smiles>

Rationale:

All three CRUs are bracket-shifted toward the central non-repeating junction unit.

All three CRUs are deemed to be in an identical environment because each is connected directly to the central non-repeating junction unit propane-1,2,3-triyl which, although it contains a substituent, has a unitary name and is therefore simple.

Name: $\alpha, \alpha^{\prime}, \alpha$ "-(2-ethylpropane-1,2,3-triyl)tris[ $\omega$-hydroxypoly(oxyethylene)]

Note: The presence of the ethyl substituent on the junction unit does not change the procedure for generating the name of the complete polymer.

Example 5.3.4. Three-arm star polymer with three identical bracket-shiftable CRUs, a simple junction unit, and three non-identical end-groups

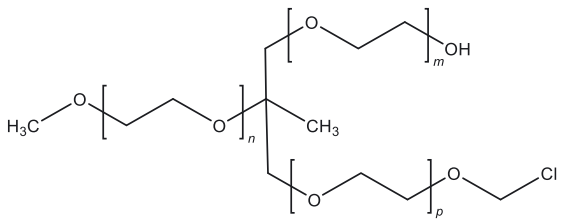

Rationale:

All three CRUs are bracket-shifted toward the central non-repeating junction unit.

All three CRUs are deemed to be in an identical environment because each is connected directly to the central non-repeating junction unit propane-1,2,3-triyl which, although it contains a substituent, has a unitary name and is therefore simple.

Name: $\omega$-(chloromethoxy)- $\omega$ "-hydroxy- $\omega^{\prime}$-methoxy- $\alpha, \alpha^{\prime}, \alpha^{\prime \prime}$-(2-methylpropane-1,2,3-triyl)tris[poly-(oxyethylene)]

Note: The three $\omega$-end-groups are cited alphabetically, not in the order $\omega, \omega^{\prime}, \omega^{\prime \prime}$.

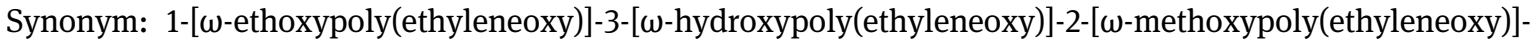
2-methylpropane

Example 5.3.5. Three-arm star polymer with three identical bracket-shiftable CRUs, a complex junction unit, and three identical end-groups 


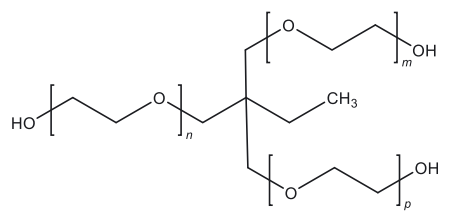

Rationale:

All three CRUs are bracket-shifted toward the central non-repeating junction unit.

Since the junction unit is generated from the branched substance 2-ethyl-2-(hydroxymethyl)propane1,3-diol, it is also branched and, therefore, it is complex. The "parent" for this compound, propane-1,3-diol, cites only two of the three hydroxy groups, which means that all other moieties are treated as substituents. Likewise, the "parent" component of the final name for the complete polymer can cite only two CRUs; the third has to be a component of a substituent.

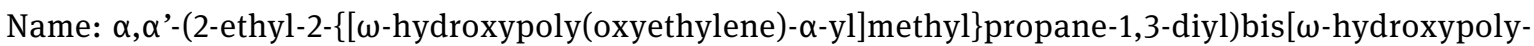
(oxyethylene)]

Synonym: $\alpha, \alpha^{\prime}, \alpha^{\prime \prime}$-(propane-1,1,1-triyltrimethylene)tris[ $\omega$-hydroxypoly(oxyethylene)]

Example 5.3.6. Three-arm star polymer with three identical bracket-shiftable CRUs and three identical endgroups

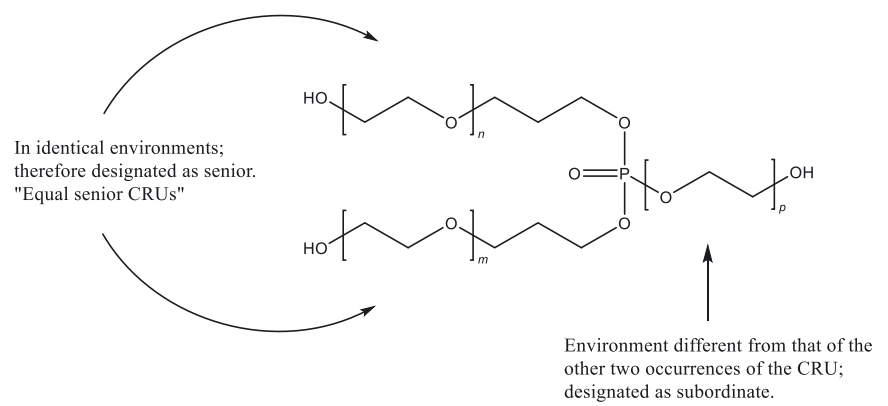

Rationale:

All three CRUs are bracket-shifted toward the central non-repeating junction unit.

The CRU attached directly to the phosphorus atom is in an environment different from that of the other two CRUs, and therefore, all three CRUs cannot be part of the "parent" component of the final name.

Name: $\alpha, \alpha^{\prime}-\{[\omega$-hydroxypoly(oxyethylene)- $\alpha$-yl]phosphorylbis(oxypropane-3,1-diyl)\}bis[ $\omega$-hydroxypoly(oxyethylene)]

Synonym: $\alpha, \alpha^{\prime}-\{[\omega$-hydroxypoly(ethyleneoxy)]phosphorylbis(oxypropane-3,1-diyl)\}bis[ $\omega$-hydroxypoly(oxyethylene)]

Further examples of the application of Nomenclature Recommendations 1-16 to various star-type irregular structure-based polymers are shown in Table 7 below. 
Table 7: Further examples of preferred names generated by application of Nomenclature Recommendations 1-16.

\section{No. Structure}
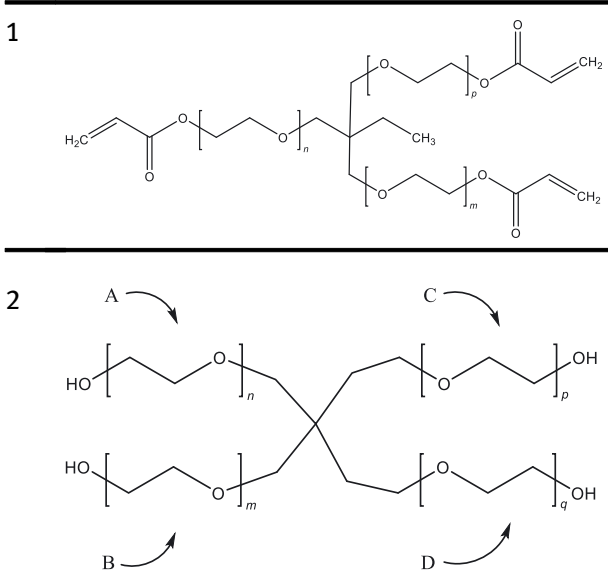

Preferred name generated according to Nomenclature Recommendations 1-16

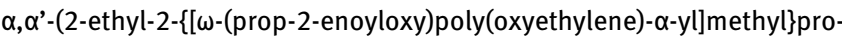
pane-1,3-diyl)bis[ $\omega$-(prop-2-enoyloxy)poly(oxyethylene)]

Synonym: $\alpha, \alpha^{\prime}, \alpha^{\prime \prime}$-(propane-1,1,1-triyltrimethylene)tris[ $\omega$-(prop2-enoyloxy)poly(oxyethylene)]

$\alpha, \alpha^{\prime}-(2,2$-bis $\{2-[\omega$-hydroxypoly(oxyethylene)- $\alpha$-yl] ethyl\}propane-

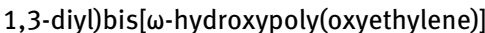

Note: $C R U s A$ and $B$ are in equal environments; $C R U s C$ and $D$ are in equal environments; selection of $A$ and $B$, instead of $C$ and $D$, as equal senior CRUs is preferred because it results in a name that is earlier in the alphabet.

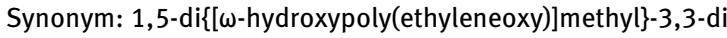
$\{[\omega$-hydroxypoly(ethyleneoxy) $]$ methyl\}pentane

3<smiles>CCC(COC(=O)C(C)O)(COC(=O)C(C)O)COC(=O)C(C)O</smiles>

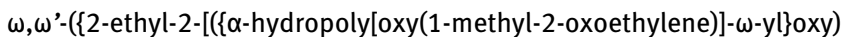
methyl]propane-1,3-diyl\}-1,3-bis(oxy))bis\{ $\alpha$-hydropoly[oxy(1-methyl2-oxoethylene)]\}

Synonym: $\alpha, \alpha^{\prime}, \alpha$ '-[propane-1,1,1-triyltrimethoxy]tris $\{\omega$-hydropoly [(2-methyl-1-oxo-ethylene)oxy]

$\alpha, \alpha^{\prime}$-(\{2-methyl-2-[ $\omega$-(propanoyloxy)poly(oxyethylene)- $\alpha$-yl]methyl\}propane-1,3-diyl)bis[ $\omega$-(acetyloxy)poly(oxyethylene)]

Synonym: $\omega, \omega^{\prime}$-di(acetyloxy)- $\omega^{\prime}-\left(\right.$ propanoyloxy)- $\alpha, \alpha^{\prime}, \alpha^{\prime \prime}$-(ethylene1,1,1-triyltrimethylene)tris(polyoxyethylene) or 2,2-di $\{[\omega$-(acetyloxy) poly(ethyleneoxy)]methyl\}-1-[ $\omega$-(propanoyloxy)poly(ethyleneoxy)] propane

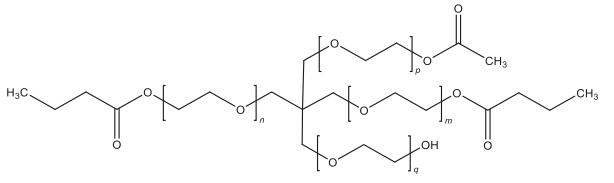

$\alpha, \alpha^{\prime}-(\{2-[\omega-($ acetyloxy)poly(oxyethylene)- $\alpha$-yl]methyl $\}\{2-[\omega$-hydroxypoly(oxyethylene)- $\alpha$-yl]methyl $\}$ propane-1,3-diyl)bis $\{[\omega$-(butanoyloxy) poly(oxyethylene)- $\alpha$-yl]poly(oxyethylene)\}

Synonym: $\omega$-acetoxy- $\omega^{\prime}$-hydroxy- $\omega^{\prime \prime}, \omega-{ }^{\prime \prime \prime}$ di(butanoyloxy)- $\alpha, \alpha^{\prime}, \alpha^{\prime \prime}, \alpha^{\prime \prime}$ '-(methanetetrayltetramethylene)tetrakis[poly(oxyethylene)] or 1-[ $\omega$ (acetyloxy)poly(ethyleneoxy)]-3-[ $\omega$-hydroxypoly(ethyleneoxy)]-2,2-di $\{[\omega$-(butanoyloxy)poly(ethyleneoxy) $]$ methyl $\}$ Propane<smiles>CCCC(=O)OCCOCCC(C)(COCCOC(C)=O)COCCOC(C)(C)O</smiles>

$\omega$-(acetyloxy)- $\omega^{\prime}$-(butanoyloxy) $\left(\alpha, \alpha^{\prime}-\{2-[\omega\right.$-hydroxypoly(oxyethylene)-

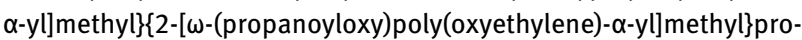
pane-1,3-diyl)bis[poly(oxyethylene)]

Note: The four different end-groups are acetyloxy, butanoyloxy, hydroxy, and propanoyloxy. The other three possible names all alphabetize later than the one shown and are therefore not preferred.

Synonym: $\omega$-(acetyloxy)- $\omega^{\prime}$-hydroxy- $\omega^{\prime \prime}$-(propanoyloxy)- $\omega^{\prime \prime \prime}$-(butanoyloxy)- $\alpha, \alpha^{\prime}, \alpha^{\prime \prime}, \alpha^{\prime \prime \prime}-($ methanetetrayltetramethylene)tetrakis[poly(oxyethylene)] or 1-[ $\omega$-(acetyloxy)poly(ethyleneoxy)]-2$\{[\omega$-hydroxypoly(ethyleneoxy)]methyl $\}-3-[\omega$-(butanoyloxy)poly(-

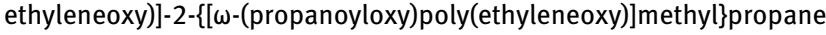




\section{SCB-6.4 Multi-branched (comb-like) polymers}

The fourth type of polymer is a multi-branched (comb-like) type with a backbone comprising several subunits, of which at least one has a connectivity of three. It can be represented, for example, as

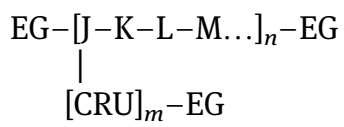

(in which $\mathrm{J}$ is the senior subunit of the $\mathrm{CRU}[\mathrm{J}-\mathrm{K}-\mathrm{L}-\mathrm{M} \ldots .$.$] )$

or

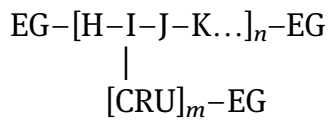

(in which $\mathrm{H}$ is the senior subunit of the $\mathrm{CRU}[\mathrm{H}-\mathrm{I}-\mathrm{J}-\mathrm{K} . .$.$] ).$

or

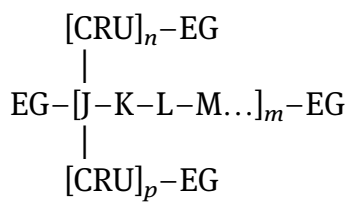

(in which $\mathrm{J}$ is the senior subunit of the CRU $[\mathrm{J}-\mathrm{K}-\mathrm{L}-\mathrm{M} . .$.$] ).$

In the first two examples, J represents the branching subunit and the other letters $(\mathrm{H}, \mathrm{I}, \mathrm{K}, \mathrm{L}$, and $\mathrm{M})$ represent non-branching subunits. In the third example, $\mathrm{J}$ and $\mathrm{K}$ represent the branching subunits and the other letters ( $\mathrm{L}$ and $\mathrm{M}$ ) represent non-branching subunits.

Note: In contrast to the types discussed above, the CRU in the side chain is virtually always different from the CRU in the main chain.

\section{Nomenclature Recommendation 18}

The multistep procedure recommended for naming these polymers is as follows:

(1) Designate moieties such as -[J-K-L-M.... $]_{n}$ - or -[H-I-J-K... $]_{n}$-as the main chain.

(2) Designate the group -[CRU $]_{n}$-EG as a substituent.

(3) Name the substituent according to Nomenclature Recommendation 5.

(4) According to previously published principles [2], name the main chain; the final name should include the name of the substituent generated in the previous step together with an appropriate locant.

The examples below illustrate the procedure.

Comb polymer with one occurrence of one type of CRU in one side chain per main-chain CRU.

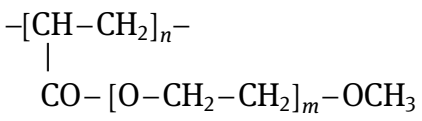

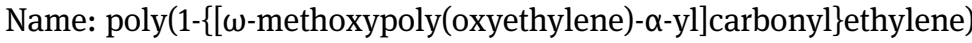

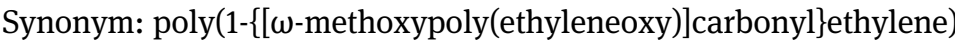

Comb polymer with one occurrence of one type of CRU in one side chain per main-chain CRU. 


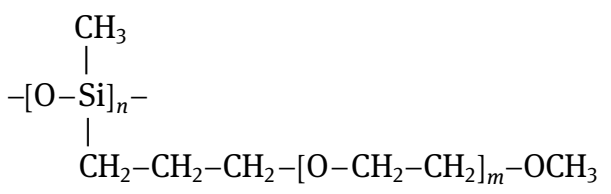

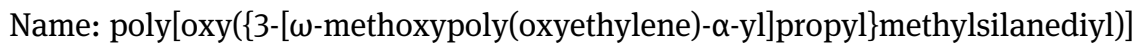

Note: name of polymeric side-chain alphabetizes before methyl group attached to silanediyl subunit.

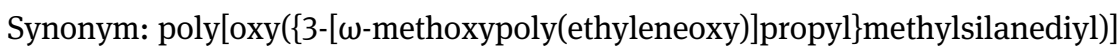

Comb polymer with one occurrence of one type of CRU in one side chain per main-chain CRU.

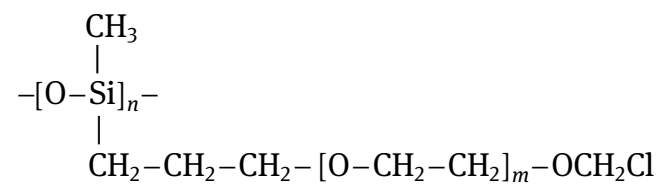

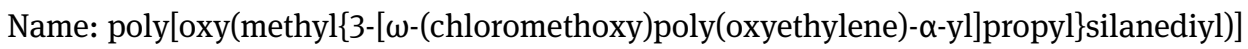

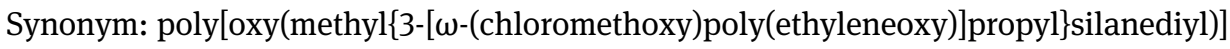

Note: name of polymeric side-chain alphabetizes after the methyl group attached to the silanediyl subunit.

Comb polymer with two occurrences of one type of CRU in two separate side chains per main-chain CRU.

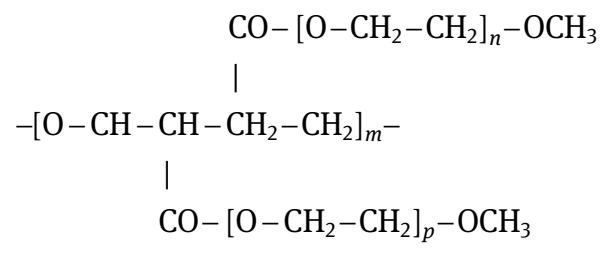

Name: $\operatorname{poly}[\operatorname{oxy}(2,3-\operatorname{bis}\{[\omega$-methoxypoly(oxyethylene)- $\alpha$-yl $]$ carbonyl $\}$ butane-1,4-diyl) $]$

Synonym: poly[oxy(2,3-bis $\{[\omega$-methoxypoly(ethyleneoxy)]carbonyl\}butane-1,4-diyl)]

\section{SCB-6.5 Multi-branched (brush-like) polymers}

The fifth type of polymer is also a multi-branched (brush-like) type with a backbone comprising several subunits, of which at least one has a connectivity of four. It can be represented, for example, as

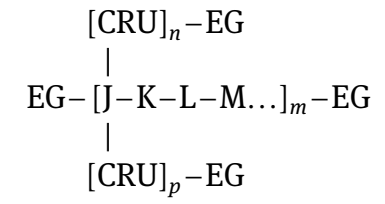

(in which $\mathrm{J}$ is the senior subunit of the $\mathrm{CRU}[\mathrm{J}-\mathrm{K}-\mathrm{L}-\mathrm{M} \ldots]$ ) or

$$
\begin{gathered}
{[\mathrm{CRU}]_{n}-\mathrm{EG}} \\
\mathrm{EG}-[\mathrm{H}-\mathrm{I}-\mathrm{J}-\mathrm{K} \ldots]_{m}-\mathrm{EG} \\
\mid \mathrm{CRU}]_{p}-\mathrm{EG}
\end{gathered}
$$

(in which $\mathrm{H}$ is the senior subunit of the $\mathrm{CRU}[\mathrm{H}-\mathrm{I}-\mathrm{J}-\mathrm{K} \ldots .$.$] ).$ 
The procedure recommended for naming these polymers is the same as for the Type Four polymers given in the previous section.

\section{Example:}

Brush polymer with two occurrences of one type of CRU in two side chains per main-chain CRU.<smiles>COCCOCCOCCOC</smiles>

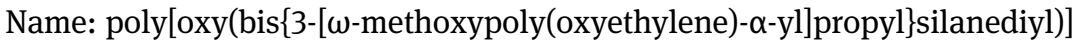

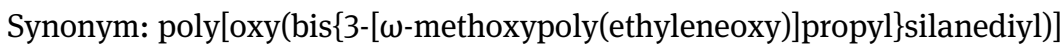

\section{Membership of sponsoring bodies}

Membership of the IUPAC Division of Chemical Nomenclature and Structure Representation for the period 2016-2017 is as follows

President: K.-H. Hellwich (Germany); Vice President: A. T. Hutton (South Africa); Secretary: R. S. Laitinen (Finland); Titular Members: O. Achmatowicz (Poland); T. Damhus (Denmark); P. Hodge (UK); R. T. Macaluso (USA); J. Nagy (Hungary); M. M. Rogers (USA); J. Vohlídal (Czech Republic); Associate Members: M. A. Beckett (UK); I. L. Dukov (Bulgaria); G. A. Eller (Austria); E. Mansfield (USA); M. A. Strausbaugh (USA); K. T. Taylor (USA); National Representatives: F. Aricò (Italy); A. M. da Costa Ferreira (Brazil); A. Fradet (France); H. W. Lee (Korea); T. L. Lowary (Canada); E. Nordlander (Sweden); M. Putala (Slovakia); A. P. Rauter (Portugal); J. P. van Lune (Netherlands); A. Yerin (Russia); Ex Officio: R. M. Hartshorn (New Zealand); G. P. Moss (UK).

Membership of the IUPAC Polymer Division Committee for the period 2018-2019 was as follows

President: G. T. Russell (New Zealand); Vice President: C. K. Luscombe (USA); Secretary: M. G. Walter (USA); Titular Members: C. Fellows (Australia); R. C. Hiorns (France); R. Hutchinson (Canada); I. Lacík (Slovakia); N. Stingelin (UK); P. D. Topham (UK); Y. Yagci (Turkey); Associate Members: S. Beuermann (Germany); M. C. H. Chan (Malaysia); C. G. dos Santos (Brazil); D. S. Lee (Republic of Korea); G. Moad (Australia); P. Théato; National Representatives: R. Adhikari (Nepal); J. He (China); M. Hess (Germany); V. P. Hoven (Thailand); C.S. Hsu (Taiwan); DP. Mallon (South Africa); O. E. Philippova (Russia); M. Sawamoto (Japan); A. Sturcova (Czech Republic); J. van Hest (Netherlands).

Membership of the Subcommittee on Polymer Terminology during the preparation of these Recommendations (2013-2019) was as follows

Chair: R. G. Jones (UK), 2006-2013; R. C. Hiorns (France), from 2014; Secretary: R. C. Hiorns (France), 20102013; C. K. Luscombe (USA), 2014-2015; P. D. Topham (UK), from 2016; Members: V. Abetz (Germany); R. Adhikari (Nepal); G. Allegra (Italy); M. Barón (Argentina); R. Boucher (UK); P. Carbone (UK); M. C. H. Chan (Malaysia); T. Chang (Korea); J. Chen (USA); C. Fellows (Australia); A. Fradet (France); F. Giuntini (UK); C. F. O. Graeff (Brazil); J. He (China); K. H. Hellwich (Germany); M. Hess (Germany); P. Hodge (UK); W. Hu (China); J. I. Jin (Korea); J. Kahovec (Czech Republic); T. Kitayama (Japan); P. Kratochvíl (Czech Republic); P. Kubisa (Poland); C. K. Luscombe (USA); M. Malinconico (Italy); P. Mallon (South Africa); J. B. Matson (USA); S. V. Meille (Italy); J. Merna (Czech Republic); G. Moad (Australia); W. Mormann (Germany); T. Nakano (Japan), C. K. Ober (USA); M. Peeters (UK); S. Penczek (Poland); O. Phillipova (Russia); M. D. Purbrick (UK); G. Raos (Italy); G. Russell (New Zealand); C. G. dos Santos (Brazil); C. Scholz (USA); S. Słomkowski (Poland); R. F. T. Steptoł (UK); N. Stingelin (UK); A. Sturcova (Czech Republic); P. Théato (Germany); J. P. Vairon (France); M. Vert (France); J. Vohlídal (Czech Republic); M. G. Walter (USA); E. S. Wilks (USA); M.-H. Yoon (Republic of Korea).

${ }^{\ddagger}$ Deceased. 


\section{References}

[1] IUPAC. Pure Appl. Chem. 74, 1921 (2002), Reprinted as chapter 15 in [2].

[2] IUPAC. Compendium of Polymer Terminology and Nomenclature: IUPAC Recommendations 2008 (the "Purple Book"). Prepared for publication by R. G. Jones, J. Kahovec, R. Stepto, E. S. Wilks, M. Hess, T. Kitayama, W. V. Metanomski, with advice from A. Jenkins and P. Kratochvíl, RSC Publishing, Cambridge, UK (2008).

[3] IUPAC. Pure Appl. Chem. 66, 873 (1994), Reprinted as chapter 17 in [2].

[4] IUPAC. Pure Appl. Chem. 65, 1561 (1993), Reprinted as chapter 16 in [2].

[5] IUPAC. Pure Appl. Chem. 80, 201 (2008).

[6] IUPAC. Pure Appl. Chem. 69, 2511 (1997), Reprinted as chapter 20 in [2].

[7] IUPAC. Pure Appl. Chem. 57, 149 (1985).

[8] IUPAC. Pure Appl. Chem. 88, 1073 (2016).

[9] IUPAC. Pure Appl. Chem. 91, 523 (2019).

[10] IUPAC. Pure Appl. Chem. 68, 2287 (1996), Reprinted as chapter 1 in [2].

[11] IUPAC. Compendium of Chemical Terminology, 2nd ed. (the "Gold Book"). Compiled by A. D. McNaught and A. Wilkinson. Blackwell Scientific Publications, Oxford (1997). XML on-line corrected version: https://doi.org/10.1351/goldbook (2006-) created by M. Nic, J. Jirat, B. Kosata; updates compiled by A. Jenkins.

[12] Nomenclature of Organic Chemistry (IUPAC Recommendations and Preferred Name 2013) (the "Blue Book"). Prepared for publication by H. A. Favre and W. H. Powell, Royal Society of Chemistry, Cambridge, UK (2013).

[13] IUPAC. Pure Appl. Chem. 89, 1695 (2017). 